\title{
2-D and 3-D modelling of wide-angle seismic data: an example from the Vøring volcanic passive margin
}

\author{
Stéphane Rouzo ${ }^{1,2,{ }^{*}}$, Frauke Klingelhöfer ${ }^{1}$, Hélène Jonquet-Kolst $\varnothing^{3}$, Ridvan Karpuz ${ }^{4}$, \\ Karl Kravik $^{3}$, Rolf Mjelde ${ }^{5}$, Yoshio Murai ${ }^{6}$, Thomas Raum ${ }^{5}$, Hideki Shimamura ${ }^{6}$, \\ Paul Williamson ${ }^{7}$ and Louis Géli ${ }^{1}$
}

(1) Department of Geodynamics and Geophysics IFREMER, Plouzané, France

(2) Present address: UMR6538 Domaines Océaniques, IUEM-UBO-CNRS, Plouzané, France

(3) Total E\&P Norge AS, Stavanger, Norway

(4) Norsk Hydro, Bergen, Norway

(5) Institute of Solid Earth Physics, University of Bergen, Bergen, Norway

(6) Institute for Seismology and Volcanology, Hokkaido University, Sapporo, Japan

(7) Total E\&P PLC's Geoscience Research Centre, Aberdeen, UK

*: Corresponding author : stephane.rouzo@univ-brest.fr

\begin{abstract}
:
This study presents the modelling of 2-D and 3-D wide-angle seismic data acquired on the complex, volcanic passive margin of the Vøring Plateau, off Norway. Three wide-angle seismic profiles were shot and recorded simultaneously by 21 Ocean Bottom Seismometers, yielding a comprehensive 3-D data set, in addition to the three in-line profiles. Coincident multi-channel seismic profiles are used to better constrain the modelling, but the Mesozoic and deeper structures are poorly imaged due to the presence of flood basalts and sills. Velocity modelling reveals an unexpectedly large $30 \mathrm{~km}$ basement high hidden below the flood basalt. When interpreted as a 2-D structure, this basement high produces a modelled gravity anomaly in disagreement with the observed gravity. However, both the gravity and the seismic data suggest that the structure varies in all three directions. The modelling of the entire 3D set of travel times leads to a coherent velocity structure that confirms the basement high; it also shows that the abrupt transition to the slower Cretaceous basin coincides in position and orientation with the fault system forming the Rån Ridge. The positive gravity anomaly over the Rån Ridge originates from the focussed and coincident elevation of the high velocity lower crust and preCretaceous basement. Although the Moho is not constrained by the seismic data, the gravity modelled from the 3-D velocity model shows a better fit along the profiles. This study illustrates the interest of a 3-D acquisition of wide-angle seismic over complex structures and the benefit of the subsequent integrated interpretation of the seismic and gravity data.
\end{abstract}

Keywords Wide-angle seismic - Sub-screen imaging - 3-D modelling - Gravity modelling 


\section{Introduction}

Sub-screen imaging has become a major concern in the study of passive margins, for both academic and industrial purposes. The disturbance of the seismic waves results either from a very strong reflection of the seismic energy or from a scattering of the energy. Sills and basaltic layers, but also salt layers commonly represent a large velocity jump across an interface and act like mirrors. On the other hand, buried flood basalts are typically characterised by a rough top surface and a heterogeneous inner structure both of which contribute to scatter the seismic energy. Conventional multi-channel seismic (MCS) surveys usually fail to obtain coherent reflectivity information from the structure below the screen. Different techniques are developed to improve the seismic image and to yield extra information from below the screens, often based on wide aperture acquisition set-ups and refracted seismic waves (Samson et al., 1995; Fliedner and White, 2001). In the present study, a wide-angle seismic (WAS) investigation was conducted on a highly volcanic passive margin, where flood basalts and sills screen out the MCS reflection structure. Three wide-angle seismic profiles were shot on the southern-most part of the Vøring basin during Spring 2000 and recorded on Ocean Bottom Seismometers (OBS), in order to complement a comprehensive survey off mid-Norway (Mjelde et al., 1992; Mjelde et al., 1997; Mjelde et al., 2001; Raum et al., 2002). 21 OBS were deployed along three profiles, intersecting over the Rån Ridge gravity high near the Jan Mayen Fracture Zone (JMFZ) (cf. figure 1). The objectives of the survey are to confirm the MCS-based interpretation of the pre-rift sediments and to better understand the 
structure of the stretched continental crust beneath the circular, $60 \mathrm{~km}$ wide gravity anomaly.

The Vøring margin is a strip of thinned continental crust that experienced a long series of extension during the Mesozoic before the Early Tertiary breakup. It consists of basins and horsts, affected by numerous volcanics, sills, and likely underplating (Eldhom and Mutter, 1986; Planke et al., 1991; Berndt et al., 2001b; Torne et al., 2003). Extensive MCS surveys have been carried out by the oil industry. The geometry of the nearly undeformed Tertiary, post rift sedimentary cover is well constrained, as are the large and deep Cretaceous basins. The Rån Ridge is a small structural high that prolongs the Gjallar Ridge fault system southwest of the Vøring basin. Its detailed interpretation is rendered difficult due to the presence of flood basalts and sills. Gernigon et al. (2003) describes it as an early Cretaceous uplift of Paleozoic to Jurassic sediments, affected by normal, northwest dipping faults that remained active later in the upper Cretaceous.

This study is an example of a WAS on a complex structure affected by basaltic screens such as floods and sills. It demonstrates how the WAS can complement a MCS survey in extracting information from the shadow zones of the MCS below the screens and in the crust. During the Vøring 2000 experiment, all the OBS were deployed before shooting, thus providing a comprehensive 3 -D dataset in addition to the three profiles.

In the first part of the study, the conventional modelling of the three profiles reveals an unexpected basement high, with only a thin layer of pre-Tertiary sediments below the basaltic screen. Although this basement high is well constrained by the WAS, it produces a 2-D 
modelled gravity anomaly that disagrees with the observed Free Air Anomaly (FAA). Because both the gravity and the MCS data suggest a 3 -D structure, in the second part of this study, we try to improve the reliability of the structure in modelling the velocity using all the travel times available, including the off-line records. The benefit of these supplementary data and of a 3-D modelling is shown, the gravity anomaly is recalculated and finally the results are discussed.

\section{2-D modelling of the in-line records}

\subsection{Modelling PROCEDURE}

The crustal structure is modelled as a succession of layers of homogeneous velocity separated by interfaces. The velocity is constrained by seismic rays refracted within the layer and recorded by different contiguous OBS. The geometry of the interfaces is inferred from the travel times of (1) rays reflected at the interface and (2) rays refracted directly beneath the interface. In this study, few wide-angle reflections were discernible in the OBS gathers, so that the layers' geometry mainly relies on refracted rays.

The OBS are relocated to correct the possible drift of the instrument on its way to the sea-floor; the water wave travel times are inverted for different water velocities to infer the best OBS position. After relocation, the offsets, i.e. the distance to the shots, is estimated. Each profile is modelled individually, following a layer stripping approach: from top to bottom, the different phases defining a layer are used to 
model the velocity and geometry. The interpretation of the seismic phases and the picking of the travel times is performed on the vertical component of the OBS records. Band-pass filtering and time and offset dependent gain are used to display the data. The complexity of the data led to an iterative reinterpretation of the seismic phases. The model is progressively constructed using as few parameters (interface nodes and velocity nodes) as possible. The modelling of the wide-angle data is performed using the ray tracing and forward modelling software package of Zelt and Smith (1992). The inversion is carried out manually, following a trial-and-error approach. Frequent checks are done in the two-way time (TWT) domain to comply with the interpretation of the coincident MCS profiles provided by TotalFinaElf Norge. However, we chose not to force the fit and for structures not reproduced by both types of data, those indicated by the refraction modelling were retained. Similarly, the fit at the intersection of the 2-D profiles has not been forced, which results in gaps and misfits from profile to profile. The goal of this paper is to present and discuss these problems in the framework of the sub-screen imaging. The 3 profiles have been modelled in the following order: L5, L2 and L6, with the description of profile 5 emphasised.

\subsection{Modelling}

\subsubsection{Profile L5}

Profile 5 is perpendicular to the JMFZ, i.e. perpendicular to the main direction of breakup. The coincident MCS profile shows the abrupt transition from the oceanic domain to the stretched continental domain 
across the JMFZ (cf. figure 2b). The base Tertiary unconformity (BTU) marks the bottom of the post rift, undeformed sediments. Below, a Cretaceous basin, bounded downward by the Base of Cretaceous Unconformity (BCU), deepens down to $7 \mathrm{~s}$ TWT toward the North-East. Notice the bright reflectors crossing each other at $6 \mathrm{~s}$ TWT, suggesting a complex, non 2-D structure. Between the Cretaceous basin and the JMFZ, a rough surface at the level of the BTU indicates the top of the basaltic inner flows, below which no reflector is visible. The lack of reflectivity has been attributed to the diffraction of the seismic energy at the top of the basalts. The thickness of the Cretaceous sediments and the depth of the basement are both obtained from the interpretation of neighbouring MCS profiles, which are also affected by basaltic screens : the interpretation beneath the screen is uncertain.

The modelling of the wide-angle data is straightforward along L5, with a good coherence and continuity of the observed phases from one OBS to the other. Below the homogeneous Tertiary lid, the model features three domains of homogeneous velocities, bounded by two sharp velocity changes (cf. figure 2c). Westward, the oceanic domain is bounded by the JMFZ below OBS 9, where mature oceanic crust is found side by side with continental crust. The second domain of relatively high velocity is observed from the JMFZ to below OBS 11. Most of this block is covered by flood basalts, and corresponds to the transparent area in the MCS section (cf. Fig. 2b). Figure 3 shows that the velocities are radically different east and west of OBS 11. This sharp velocity change is remarkably well documented by all OBS. Across this structure, the velocity diminishes from $\sim 6 \mathrm{~km} / \mathrm{s}$ west of OBS 11 to 
$\sim 4 \mathrm{~km} / \mathrm{s}$ east of OBS 11. Eastward, the third domain is characterised by slow velocities within the deep Cretaceous basin.

2.2.1.1. The flood basalts and below The inner basalt flows do not appear in the wide angle data along L5, neither as clear reflected phases nor as first arrival refracted phases. This characteristic unit has been reported in the area to exhibit a variety of velocities and thicknesses, as low as $3.4 \mathrm{~km} / \mathrm{s}$ and a few tens of meters thick (pers. comm. L. Gernigon). In the modelling, a layer is introduced, bounded above by the MCS reflector of the basalts, and an a priori velocity of $3.4 \mathrm{~km} / \mathrm{s}$ is assigned, so that no first arrival is generated. In the absence of wideangle reflection, the thickness of this layer is constrained to about $1 \mathrm{~km}$ by the $5 \mathrm{~km} / \mathrm{s}$ refracted phase observed on OBS 9, 10 and 11, which provides a good fit with the Campanian MCS horizon. Finally, wideangle seismic data reveal nothing about the flood basalts themselves, but indicate that not more than $1 \mathrm{~km}$ of sediments having the typical velocity of the upper Cretaceous sediments are present below the screen. Below, a refractor underlining the transition from 5 to $6 \mathrm{~km} / \mathrm{s}$ is found at a depth of about $6 \mathrm{~km}$. This interface may correspond to the top of basement, considering that $6 \mathrm{~km} / \mathrm{s}$ is a typical crustal velocity.

2.2.1.2. The Cretaceous basin The deep Cretaceous basin is characterised by low velocities, ranging from 3.4 to at most $4 \mathrm{~km} / \mathrm{s}$. A step-back in the first arrivals suggests the presence of a velocity inversion in its deeper, highly reflective part. The bottom of the basin, associated with the 4 -to- $5 \mathrm{~km} / \mathrm{s}$ interface, is found $0.5 \mathrm{~s}(\sim 1 \mathrm{~km})$ deeper

voeringPapier_corr2_net.tex; 31/10/2005; $17: 25 ;$ p.8 
than the BCU horizon. Introducing a plausible velocity inversion in the deep Cretaceous basin produces no significant effect.

2.2.1.3. The transition below $O B S 11$ Probably the most striking feature of this profile is the abrupt transition between the interpreted basement high beneath the inner flows and the Cretaceous basin. Whereas MCS data clearly show a gradual deepening of the basin towards the north-east, the WAS data on all OBS coherently suggest that this transition occurs over a short horizontal distance below OBS 11. Indeed, OBS 11 shows a drastic asymmetry in the slope of the first arrivals (cf. fig. 3), implying that the velocities are radically different east and west of OBS 11. The first arrivals recorded on the other OBS for various offsets and steep emerging rays suggest that the velocity change is sharp and affects a large depth range. Although the WAS is inherently not dedicated to image vertical discontinuities, the best fit to the data is obtained using a very narrow velocity transition.

This velocity distribution is unexpected considering the MCS: the reflection seismic shows the bottom of the Cretaceous Basin (BCU) as well as the intra Cretaceous horizons (Intra Campanian and Top Turonian) getting shallower toward OBS 11, while the WAS requires low velocities as deep as $8 \mathrm{~km}(6.2 \mathrm{~s}$ TWT) to delay the faster phases east of OBS 11. Subsequently, the rim of the Cretaceous basin is not "seen" at the same depth by the WAS and the MCS.

This significant mismatch between the two seismic tools may be investigated in terms of $3-\mathrm{D}$ effects. 
2.2.1.4. Below the $B C U$ The $5 \mathrm{~km} / \mathrm{s}$ layer is found below the flood basalts as well as below the Cretaceous basin. These pre-Cretaceous sediments comprise most of the Transform Margin High. The top of a $6 \mathrm{~km} / \mathrm{s}$ layer is well constrained from the JMFZ to OBS 11 at a nearly constant depth of $6 \mathrm{~km}$, and is interpreted as a basement high. At about $14 \mathrm{~km}$ depth, the velocity increases to a value higher than $7 \mathrm{~km} / \mathrm{s}$ all along the continental part of the profile, in good agreement with other estimations (Mjelde et al., 2002; Korenaga et al., 2000). The $7 \mathrm{~km} / \mathrm{s}$ interface is actually the deepest structure constrained by the WAS. Surprisingly, this interface is consistent with the MCSinterpreted basement beneath the screen. Most of the OBS gathers show single phases at far offsets, not coherent from one OBS to the other and associated with unrealistically high apparent velocities, so Moho depth could not be modelled.

2.2.1.5. The oceanic domain The oceanic domain, west of the JMFZ, is constrained by two OBS. The lower most $4 \mathrm{~km}$ of the oceanic crust show a velocity as high as $7 \mathrm{~km} / \mathrm{s}$, in good agreement with intersecting profile $8 \mathrm{~b}-96$. The JMFZ has been introduced as a sharp discontinuity on the basis of geological considerations.

2.2.1.6. 2-D gravity modelling The correlation between seismic velocity and density is commonly used to provide an independent check on the crustal velocity model through the modelling of the gravity anomaly. A modelling of the FAA is proposed, following the conventional approach: the velocity model is converted to density using the Nafe-Drake empirical velocity-density relationship (Ludwig et al., 1970) 
and the gravity anomaly is calculated using the Talwani et al. (1959) algorithm. The density structure is assumed to be constant in the direction perpendicular to the profile. Although the absence of the Moho interface prevents complete and thorough gravity modelling, this approach can still help in controlling the compatibility of the overall velocity structure versus the gravity signal.

The predicted gravity anomaly corresponding to the velocity model along L5 is shown in figure 2a (light blue dotted line) together with the shipboard free air gravity anomaly (red dashed line). The predicted gravity anomaly differs from the observed anomaly mainly on two points: first, it features a long wavelength slope that is not observed and second, the observed anomaly shows a wide high whereas the predicted one shows a narrow high centred west of OBS 11. Indeed, the predicted anomaly reflects the bi-modal distribution of the velocities, with high velocities west of OBS 11 and low velocities east of OBS 11. The green dotted line in figure $2 \mathrm{a}$ corresponds to the gravity signal after an estimated crustal root assuming isostatic equilibrium is added. Densities are then hand-edited to further reduce the discrepancy. These ad hoc corrections are lower than $5 \%$, which is acceptable considering the scatter of the data defining the velocity-density relationship. The fit is improved, with a clear attenuation of the long wavelength. Reducing further the misfit at shorter wavelength implies significant density variations which are not observed in the velocities. In the absence of additional information, we consider that the fit to the gravity cannot be improved further. Therefore, the gravity and the velocity modelling along L5 are not fully consistent in a 2-D framework. 


\subsubsection{Profile L2}

Profile L2 is parallel to the JMFZ, i.e. the main direction of deformation during the continental break-up. On the coincident MCS profile (figure 4b), a sill complex is identified between OBS 18 and OBS 11 at $4 \mathrm{~s}$ TWT. Other bright spots are interpreted as sills further to the south-east in the Cretaceous basin. The interpretation of the profile is difficult below the basaltic screens, in particular north of OBS 11. The depth of the basement mainly results from the interpretation of neighbouring and intersecting MCS profiles. It suggests that the basement consists of a set of highly tilted blocks, among which the most prominent one is right below the sill complex.

The WAS data quality is poorer than along L5, with lateral amplitude variations likely related to the presence of sills at various depth. Moreover, the apparent velocities vary significantly from one OBS to the other, so that the lateral continuity of the layers is difficult to model.

Figure 4c shows the final velocity model along line L2. The southeastern most OBS 5 gather suggests that a shallow sill may generate a first arrival, but it is found at a shallower depth than the one reported in the MCS interpretation. Few OBS recorded large offset travel times that can be consistently interpreted and modelled. The interpretation of the MCS played an important role in suggesting the structure, even at depth. Only one layer could be defined in the 5 -to- $6 \mathrm{~km} / \mathrm{s}$ range, so the thickness of the pre-Cretaceous cannot be estimated. The bottom of the $7 \mathrm{~km} / \mathrm{s}$ interface has been tentatively introduced on the basis of wideangle reflection interpretation. No diving phase could be identified, that would constrain the velocity beneath this interface. Thus, the interpre- 
tation of this interface as the Moho cannot be clearly demonstrated. The structures along this profile are generally not as well constrained as along line L5, and the fit at the intersection is not perfect.

\subsubsection{Profile $L 6$}

Similarly to lines L5 and L2, flood basalts along L6 cover the western part of the continental crust, masking much of the reflectivity underneath (figure 5b). The MCS basement is unconstrained along this profile, whereas the integrated interpretation suggests that a relatively thick Cretaceous unit underlies the inner flows. The modelling of the velocities largely benefited from the shallow structures observed on the MCS profiles (cf. figure 5c). As for L5 and L2, flood basalts have no specific signature in the first arrivals recorded on OBS. The Cretaceous unit is found to deepen more than expected, forming a basin below the flood basalts. At greater depths, the fit of the data worsens, suggesting that some structures are missing in the model. The large dome-like structure of the $7 \mathrm{~km} / \mathrm{s}$ interface is mainly constrained by larger offsets on OBS 16 and 17 (see figure 6), whereas the overlying OBS 18, 19 and 23 do not provide either near-offset or reciprocal large offset ray paths. The best result is obtained using head waves. Similar to L5, the modelled 2-D gravity anomaly results in large misfits.

\subsection{2-D MODELLING: DISCUSSION}

The Paleozoic/Early Mesozoic structures are strongly tectonised in all three directions. The unexpected structural high observed along L5 is associated with anomalously thin Cretaceous deposits. The 6 to $7 \mathrm{~km} / \mathrm{s}$ 
interface below this basement high remains flat. The absence of seismic data constraining the Moho discontinuity may originate from the conjugated effects of the screens and the strongly tectonised structure of the upper crust. Velocities of $7 \mathrm{~km} / \mathrm{s}$ are common in the lower crust of volcanic margins (Holbrook et al., 1992). They are often attributed to the presence of mafic igneous bodies intruding the base of the crust. In this study, neither the WAS data nor the gravity constrain the nature of the deep crust, because the Moho is lacking and the profiles are too short to exhibit variations. This velocity is in agreement with the values inferred from other experiments in the neighbourhood (Berndt et al., 2001a; Mjelde et al., 2001; Korenaga et al., 2000).

The relatively poor fit at the intersections is significant, but acceptable considering the large lateral velocity variations introduced at or close to the intersections. A representative example is the intersection of lines L5 and L2 below OBS 11.

At this stage of the interpretation, the modelling of the WAS confirms the structure of the Cretaceous unit where the MCS maps it with confidence and suggests that more Cretaceous sediments are present below the screen along L6, in association with Paleozoic-Early Mesozoic sediments. On the other hand, the small Cretaceous basin expected below the screen along L5 is not observed. There is room for at most 1000 meters of Cretaceous strata, if any, on top of the basement high.

However, the modelling of the wide-angle data suffers from three major problems: (1) none of the three profiles constrains the structure of the crust below $15 \mathrm{~km}$ depth, (2) the velocity structure conflicts with the MCS structure at the rim of the Cretaceous basin and (3) the gravity modelling does not support the velocity model, especially 
along line L5. Point (1) results directly from the complexity of the upper structures (screens, sills, tectonics) and the subsequent complexity of the data. Points (2) and (3) are not trivial, because dense, coherent and good quality WAS data disagree with the MCS image of the basin's shoulder and the gravity signal. We propose that both points (2) and (3) may originate from the complex geometry of the structures. Somehow, the normal incidence MCS images a different structure than the one crossed by turning rays recorded on OBS. Similarly, the gravity signal along L5 may partly result from off-profile sources. Thus, the apparent and unacceptable incompatibility between the WAS, the MCS and the gravity would reflect the intrinsic three-dimensionality of the crustal structure. This assumption is supported by the following observations: first, profile L5 is oriented very obliquely to the faults and discontinuities (cf. fig. 1). Secondly, wide-angle reflections from the BCU are observed at the right time, but without the related refracted phase. Third, the gravity anomalies feature large gradients across the strike of the profiles (especially L5), suggesting that important density anomalies are not centred below the seismic lines. Since all OBS recorded all shots, we used the complete, 3-D dataset to see if this assumption can be further investigated. 


\section{3-D modelling of the complete dataset}

\subsection{TOMOGRAPHIC METHOD}

\subsubsection{Inversion tool}

In order to uniformly model the entire set of 3-D arrival times, simultaneous and automatic inversion of the seismic travel times was performed. FAST (First Arrival Seismic Tomography (Zelt and Barton, 1998)) has been used because it is simple to set and handle. This tool uses only the first arrivals, which requires the lowest level of data interpretation. First arrivals constrain the continuously varying velocity beneath the sea floor. The only parameters of the inversion are the evenly spaced velocity nodes. The forward calculation of the travel times and ray paths uses velocities sampled on a constant, square grid while the inversion process uses velocities on a coarser grid. The tomographic method is a regularised inversion incorporating a userspecified combination of smallest, flattest and smoothest perturbation constraints. A starting -or background- model is needed for the iterative approach. The constraints are applied to the model perturbation with respect to the background model. New ray paths are calculated for each iteration. The interface of the sea floor can be defined, below which the velocity is inverted.

\subsubsection{The modelling procedure}

3.1.2.1. Defining the geometry and the starting model. The sides of the inversion box are parallel to profiles 2 and 5, and coincide with the surrounding 1996 profiles (see figure 1). The forward grid size is set to 
$1 \mathrm{~km}$ in all 3 directions while the inverse grid is $2 \times 2 \mathrm{~km}^{2}$ horizontally and $1 \mathrm{~km}$ vertically. The $180 \times 160 \times 25 \mathrm{~km}^{3}$ box is then defined by 757666 model nodes and 180000 inversion cells.

The inversion technique requires the starting model to be close from the final model, in order to fulfil the linearisation assumption. On the other hand, the starting model is expected to contain as little a priori information as possible. A starting model is built using a 1-D vertically varying velocity based on the velocities averaged over the three 2-D profiles and the bathymetry. With no lateral velocity variation, this starting model does not favour any solution. Because the 2-D models feature strong horizontal velocity gradients, an alternative starting model is constructed, in order to assess the convergence of the final model, i.e. its dependence on the starting model. It is built using the large scale structures imaged along the 1996 and 2000 2-D profiles.

3.1.2.2. Interpretation of the seismograms. The first arrivals are picked manually as a single phase on the vertical component of the OBS. The poorly constrained, far-offsets events are not considered. The seismic signal is preferentially left unprocessed, but noisy and complex data benefited from predictive deconvolution and band-pass filtering. The principle of travel time reciprocity (Zelt and Forsyth, 1994) is used to better identify the first arrivals from one line to the other. Figure 7 shows two examples of off-line records. The first one is relatively good, with high amplitude, continuous first arrivals. The bump in the first arrivals is related to a strong local increase in the velocities. The second example displays a record of poor quality where the first arrivals are identified in the low amplitude early events. Picking of the first 
arrivals on the 58 records resulted in 17036 travel times (figure 8a). Figure $8 \mathrm{~b}$ shows the distribution of travel times versus offset (distance source-receiver). Compared to other studies (Zelt and Barton, 1998; Schlindwein et al., 2003), travel times are much more scattered, which reflects larger lateral velocity variations. Finally, only one fourth of the travel times picks were actually inverted (4239 picks) to reduce the computation time. This reduction does not significantly affect the final velocity model.

The estimation of the pick uncertainty is an important issue, which relates to data quality and influences the model resolution. Zelt and Forsyth (1994) proposed an empirical estimation of the uncertainty based on the signal-to-noise ratio for each pick. Applied to our dataset, this led to an assignment of the largest uncertainty to nearly $60 \%$ of the picks, which suggests that the data quality is relatively poor, for the moderate mean offsets (cf. the dataset in Zelt and Forsyth, 1994). The uncertainty assigned to short offset arrivals is too low to be compatible with the $1 \mathrm{~km}$-step discretisation of the sea floor. A smaller grid size did not satisfactorily solve the problem. Finally a constant uncertainty of $100 \mathrm{~ms}$ was assigned to all travel times picks, regardless of amplitudes or offsets. This value compares well with the constant uncertainty of $70 \mathrm{~ms}$ used by Schlindwein et al. (2003) for offsets lower than $50 \mathrm{~km}$ and a simpler structure.

3.1.2.3. First insights from the off line dataset. The modelling of the 2-D, in-line WAS data highlights the drastic velocity change along profile 5 below OBS 11. Figure 9 shows records on OBS 10 and 13 of line L2. Although both OBS are equally distant from the seismic 
line and OBS 10 is $800 \mathrm{~m}$ deeper than OBS 13, the first arrival is more than 1.5 s sooner on OBS 10 than on OBS 13. This considerable delay cannot be explained by the presence of the Cretaceous basin, which is actually thin below OBS 13. This offers tangible evidence that the average velocity is much lower towards OBS 13 than towards OBS 10. This is also observed by different configurations (for instance shots along L2 recorded by OBS 16 and 17, not shown).

\subsection{Modelling the 3-D Dataset}

A typical inversion run takes about 45 minutes on an AMD Athlon 1.4 Ghz with about 750000 parameters and more than 4200 travel time data. Thus the influence of the main parameters could be tested repeatedly. Parameter $\lambda$ determines the trade-off between achieving a minimum data residual and a smooth model. The larger value of $\lambda$ is determined iteratively, for which a normalised misfit $\chi^{2}$ of 1 is reached. This justifies the choice of the simplest model that fits the observed travel times within the pick uncertainty. Moreover, a smooth rather than flat solution is preferred, with equal smoothness in all three directions $\left(s_{z}=1\right)$. A smooth rather than least perturbed model is also fovored $(\alpha=0.9)$.

The final velocity model is shown in figure 10 as horizontal slices every two $\mathrm{km}$ in depth. Five non-linear iterations are needed to reach

a $\chi^{2}$ of 1 . Most the travel time residuals are within the $+/-100 \mathrm{~ms}$ interval, and the residual times are symmetrically distributed apart from 0 (no bias, cf. figure 11b). At shallow depth, the background velocity is modified in the vicinity of the OBS. Good horizontal coverage 
is obtained for depths ranging from 10 to $15 \mathrm{~km}$. The off-line OBS 33 constrains the deep Cretaceous basin between L2 and L5. The deepening of the small Cretaceous basin between L2 and L6 is documented off-line as well. The high velocity below L5 is reproduced, as well as the sharp transition towards the low velocity of the Cretaceous Basin. Figure 10b shows that this transition is very narrow and corresponds in direction and position to the early Cretaceous faults forming the Rån Ridge (fig. $10 \mathrm{~b}$ at $9 \mathrm{~km}$ depth). Below $13 \mathrm{~km}$ depth, the main feature is the strong increase of the velocity at the intersection of lines L2 and L6. Below $15 \mathrm{~km}$ depth, the velocity there reaches unrealistically high values, while the resolution worsens (cf. fig. 10d). Bounding the velocities at each iteration led to the development of small scale instabilities and to a poorly converging solution. The 2-D modelling of L2 and L6 did not require so high velocities: the 6 -to- $7 \mathrm{~km} / \mathrm{s}$ interface features a large dome-like structure below OBS 18, that accounts for apparent velocities much higher than $7 \mathrm{~km} / \mathrm{s}$. In the absence of dual illumination of the structure, the 3-D inversion process favours a strong and focused velocity increase at depth rather than the expected shallower but moderate increase of the velocity. The lack of reciprocal rays has been solved in 2-D by using velocity interfaces constrained by the MCS interpretation. These unrealistic velocities highlight a weakness of the tomographic inversion for complex structures constrained by too few travel times picks.

An analysis has been carried out to estimate the contribution of the only $3-\mathrm{D}$, off-line data on the modelling of the velocities. All parameters defining this experiment are identical to the one leading to the velocity structure depicted in figure 10, but the data only include 
travel times of off-line records (no decimation is applied). Figure 12 shows that along a vertical plane coincident with profile 5 , most of the structures observed through the 2-D modelling and the inversion of the complete 3-D dataset are recovered. The basement high, the large velocity gradient beneath OBS 11 and the low velocity at the rim of the Cretaceous basin are required to insure a proper fit to the off-line travel times. Thus, the WAS interpretation is reinforced at the expense of the MCS interpretation.

\subsection{Resolution Analysis}

The resolution analysis consists in quantifying the reliability of the different structures revealed by the inversion process. A first insight is provided by travel time residuals. An acceptable convergence is reached, with all travel time residuals significantly reduced after inversion, without any bias or major conflict (cf. figure 11). The plot of the ray coverage, i.e. the density of rays, shows the areas where the velocity model is well constrained (figure 10c) and offers a first estimate of the spatial resolution. The 2-D oriented acquisition geometry leads to a relatively narrow volume well constrained by rays travelling at various depths and azimuths, centred on the intersection of the lines. The sectors between the profiles show an acceptable coverage at specific depths, depending on the source-receiver distance.

The resolution scale, or the ability of the seismic experiment (including the acquisition set-up as well as the inversion process) to resolve lateral variations of the velocity is assessed with "checkerboard" tests (Zelt and Barton, 1998). A $\pm 5 \%$ bi-periodic, square-pattern pertur- 
bation is added to the final velocity model and synthetic travel times are calculated. A Gaussian noise with a standard deviation equal to the pick uncertainty $(100 \mathrm{~ms})$ is added to the synthetic travel times before an inversion is carried out. The same parameters are used as for the final inversion and the velocity model to test is the starting model. The recovered checkerboard model is the difference between the final model obtained using the synthetic data and the model to test. For a $60 \mathrm{~km}$ wavelength perturbation (figure 10d), the recovered checkerboard shows that velocity structures of $30 \mathrm{~km}$ can be reliably imaged in this experiment down to about $12 \mathrm{~km}$ depth beneath the lines. The $40 \mathrm{~km}$-wide checkerboard patterns can be followed down to $16 \mathrm{~km}$ (not shown). The set-up of this experiment clearly does not offer a widespread ray coverage as would be provided by an array of OBS/seismic lines (cf. Zelt and Barton, 1998 and Schlindwein et al., 2003); however, a resolution of 30 to $40 \mathrm{~km}$ is reached on the target of the study, located at the intersection of the lines.

Two different starting models have been tested to estimate the degree of dependence of the final model and the convergence of the inversion (cf. 3.1.2.1). Figure 13 shows the difference between the final models obtained using the 1-D and 3-D starting models. Across broad regions the differences are in the $+/-5 \%$ range, suggesting that the inversion is robust and the influence of the starting model is low. In particular, the difference remains low at the centre of the box (OBS 1811) where high horizontal velocity gradients are observed. Indeed, the only noticeable difference is that the locally stronger vertical velocity gradient brings out some rays at greater depth $(18-20 \mathrm{~km})$ using the 3-D starting model.

voeringPapier_corr2_net.tex; 31/10/2005; $17: 25 ;$ p.22 


\subsection{3-D GRAVITY MODELLING}

Because a density anomaly affects the gravity over horizontal distances on the order of its depth, the 3-D gravity modelling is expected to better account for the effect of remote sources. The 3 -D velocity model is first converted to a density model using the same Nafe-Drake relationship (Ludwig et al., 1970) as for the 2-D gravity modelling, and is then extended horizontally over $60 \mathrm{~km}$ with constant densities. The gravity anomaly is described as the convolution of a gravity kernel with the density field, Boulanger and Chouteau (2001). For $M$ square prisms of constant density $\rho$, the gravity $g_{i}$ estimated at the centre of the top surface of the prism $i$ express as:

$$
g_{i}=\sum_{j=1}^{M} G_{i j} \rho_{j}
$$

with $G_{i j}$ the kernel described analytically:

$G_{i j}=-\gamma \sum_{p=1}^{2} \sum_{q=1}^{2} \sum_{s=1}^{2} \mu_{p q s}\left[a_{p} \ln \left(b_{q}+r_{p q s}\right)+b_{q} \ln \left(a_{p}+r_{p q s}\right)-c_{s} \arctan \left(\frac{a_{p} b_{q}}{c_{s} r_{p q s}}\right)\right]$

where

- $\gamma$ is the universal gravitational constant;

- $\mu_{p q s}=(-1)^{p}(-1)^{q}(-1)^{s}$ with indexes $p, q, s=1,2$ referring to 2 opposite corners of the $j^{t} h$ prism contributing to the anomaly $g_{i}$;

- $a_{p}, b_{q}$ and $c_{s}$ are the components parallel to x, y and z, respectively of the distance between the $i^{t} h$ observation point and one of the two corners of the $j^{t h}$ prism. $r_{p q s}=\left(a_{p}^{2}+b_{q}^{2}+c_{s}^{2}\right)^{\frac{1}{2}}$ defines this distance (See Boulanger and Chouteau (2001) for more details). 
In order to insure a better continuity of the structures away from the area actually crossed by seismic rays, we chose to model the gravity for the experiment using the 3-D initial model (cf. 3.1.2.1 and 3.3). Figure 14 shows the map of the predicted gravity anomaly, together with the observed one. The predicted gravity reproduces the central positive anomaly and the surrounding basins with a comparable amplitude.

Four differences are discernible in figure 14: (1) a long wavelength is present, mainly in the direction perpendicular to the fracture zone. This likely relates to the missing Moho and its associated isostatic root (figure 2a). (2) The positive anomaly between OBS 9 and 10 (line L5) results from the step in the discretised bathymetry at the JMFZ (cf. Fig $10 \mathrm{~b}$ at 5 and $7 \mathrm{~km}$ depth). (3) The extent of the central anomaly is too focused. (4) The positive anomaly between the central anomaly and the fracture zone is observed to be narrower and to the right of the predicted one. This may come from the poor coverage of the shallow structure apart from L5.

The gravity modelling appears to have improved with a 3-D approach along lines L5 and L2 (cf. fig. 2a and 4a). However, without additional information on the Moho below the basement high, it is not possible to go any further. As it is, the model simply shows that the effect of the density anomaly beneath the Rån Ridge can extend up to L5, and that the basement high along L5 induces a relatively low gravity anomaly. 


\section{Discussion}

The inversion of the 3-D seismic data set fully validates the 2-D modelling and the necessity to have a basement high from the JMFZ to OBS 11, yielding to an anomalously low velocity further east ; the sharp velocity gradient beneath OBS 11 is also reproduced. The mismatch between the MCS and the WAS is confirmed, but it can be re-investigated through the $3-\mathrm{D}$ development. The transition from a fast-to-slow velocity occurs along a line 45 degree oblique to line L5 (cf. fig. 10b from 5 to $10 \mathrm{~km}$ depth), coincident with the easternmost fault of the Rån Ridge. Such an obliquity may be at least partly responsible for the discrepancy between the normal incidence reflection seismics and the wide angle refraction travel times.

The 3-D model offers the possibility to interpret the geology by comparing structures rather than profiles. The central gravity high over the Rån Ridge mainly originates from a dome involving the preCretaceous basement, crust and high velocity lower crust; coincident shallow sills may contribute to this positive anomaly as well. The deflection of the top high-velocity lower crust compares well with other studies in the area (Raum et al., 2002). Compared to the Gjallar

Ridge (Gernigon et al., 2004), the gravity anomaly is enhanced by the coincident basement and pre-Cretaceous high on top of the deep doming.

The gravity anomaly map in figure 1 and 14a shows an elongated positive anomaly, associated to the Rån Ridge faults system. The predicted gravity induced by the basement high compares well with this elongated gravity high, which suggests that it is part of the Rån ridge 
and may uplifted during the early Cretaceous (see also the reflectors parallel to the slope of the Cretaceous basin, figure $2 \mathrm{~b}$ ), which agrees with other studies (Gernigon et al., 2004). Both the gravity and WAS suggest that the basement high beneath L5 has a restricted extension. The 3-D modelling also shows that the basement high is bounded southward by a several $\mathrm{km}$ high normal fault, already mapped as a major fault shaping the Gjallar Ridge - Rån Ridge system. So far, this structure is unique on the Vøring Plateau in bringing the basement as shallow as 6 to $7 \mathrm{~km}$ depth, leaving at most 1000 meters of Cretaceous on top of the pre-Cretaceous sediments.

The lack of constraints on the Moho depth is a major limitation in this study. As suggested by Peirce and Day (2002), additional lines surrounding the Rån Ridge would have provided a wider range of offsets and azimuths. However, it is important to emphasise the benefit of this 3-D approach, since the 2-D based modelling conflicted with both the gravity and the MCS interpretation. First, the 3-D data set confirms the 2-D interpretation at the expense of the MCS interpretation. Secondly, the 3-D effects of the complex structure on the gravity can be modelled properly and the fit to the observation is improved.

\section{Acknowledgements}

This study was funded by TotalFinaElf Exploration Norge Research Centre and contributed to the "Sub-Basalt Imaging Project". ConocoPhillips, Norsk Hydro, RWE-DEA, and Petoro are acknowledged for granting access to the data and permission to publish it. The GMT soft- 
ware of Wessel and Smith (1991) has been used extensively during this study. Two anonymous reviewers helped to improve the manuscript.

\section{References}

Andersen, O. B. and P. Knudsen: 1998, 'Global marine gravity field from the ERS-1 and Geosat geodetic mission altimetry'. J. Geophys. Res. 103(C4), 8129-8137.

Berndt, C., R. Mjelde, S. Planke, H. Shimamura, and J. Faleide: 2001a, 'Controls on the tectono-magmatic evolution of a volcanic transform margin: the Voring Transform Margin, NE Atlantic'. Mar. Geophys. Res 22, 133-152.

Berndt, C., S. Planke, E. Alvestad, F. Tsikalas, and T. Rasmussen: 2001b, 'Seismic volcanostratigraphy of the Norwegian Margin: constraints on tectonomagmatic break-up processes'. Journal of the Geological Society, London 158, 413-426.

Boulanger, O. and M. Chouteau: 2001, 'Constraints in 3D gravity inversion'. Geophys. Prospect. 49, 265-280.

Eldhom, O. and J. Mutter: 1986, 'Basin structure of the Norvegian Margin from analysis of digitally recorded sonobuoys'. J. Geophys. Res. 91, 3763-3783.

Fliedner, M. M. and R. White: 2001, 'Sub-basalt imaging in the Faeroe-Shetland Basin with large-offset data'. First Break 19, 247-252.

Gernigon, L., J. Ringenbach, S. Planke, and B. L. Gall: 2004, 'Deep structures and breakup along volcanic rifted margins: insights from integrated studies along the outer Vøring Basin (Norway)'. Marine and Petroleum Geology 21, 363-372.

Gernigon, L., J. Ringenbach, S. Planke, B. L. Gall, and H. Jonquet-Kolstø: 2003, 'Extension, crustal structure and magmatism at the outer Vøring Basin, Norwegian margin'. Journal of the Geological Society, London 160, 197-208.

Holbrook, W., W. Mooney, and N. Chistensen: 1992, Continental Lower Crust, Vol. 23 of Dev. Geotectonics, Chapt. The seismic velocity structure of the deep continental crust, pp. 1-43. Elsevier, New York.

Korenaga, J., W. Holbrook, G. Kent, P. Kelemen, R. Detrick, H. Larsen, J. Hopper, and T. Dahl-Jensen: 2000, 'Crustal structure of the Southeast Greenland margin 
from joint refraction and reflection seismic tomography'. J. Geophys. Res. 105, $21591-21614$.

Ludwig, J. W., J. E. Nafe, and C. L. Drake: 1970, The Sea, Vol. 4, Chapt. Seismic refraction, pp. 53-84. New York: Wiley.

Mjelde, R., P. Digranes, M. Van Schaak, H. Shimamura, H. Shiobara, S. Kodaira, O. Naess, N. Sorenes, and E. Vagnes: 2001, 'Crustal structure of the outer Voring Plateau, offshore Norway, from ocean bottom seismic and gravity data'. $J$. Geophys. Res. 106(B4), 6769-6791.

Mjelde, R., J. Kasahara, H. Shimamura, A. Kamimura, T. Kanazawa, S. Kodaira, T. Raum, and H. Shiobara: 2002, 'Lower crustal seismic-anomalies; magmatic underplating or serpentinized peridotite? Evidence from the Vøring Margin, NE Atlantic'. Mar. Geophys. Res.

Mjelde, R., S. Kodaira, H. Shimamura, T. Kanazawa, H. Shiobara, E. W. Berg, and O. Riise: 1997, 'Crustal structure of the central part of the Vøring basin, midNorway margin, from ocean bottom seismographs'. Tectonophys. 277, 235-257.

Mjelde, R., M. A. Sellevoll, H. Shimamura, T. Iwasaki, and T. Kanazawa: 1992, 'A crustal study off Lofoten, N. Norway, by use of 3-component ocean bottom seismographs'. Tectonophys. 212, 269-288.

Peirce, C. and A. Day: 2002, 'Ocean-bottom seismograph tomographic experiments - a consideration of acquisition geometries vs. resources'. Geophys. J. Int. 151, $543-565$.

Planke, S., J. Skogseid, and O. Eldholm: 1991, 'Crustal structure off Norway, 62 to 70 north'. Tectonophys. 189, 91-107.

Raum, T., R. Mjelde, P. Digranes, H. Shimamura, H. Shiobara, S. Kodaira, G. Haatvedt, N. Sorenes, and T. Thorbjornsen: 2002, 'Crustal Structure of the Southern part of the Voring Basin, Mid-Norway Margin, from wide-angle seismic and gravity data'. Tectonophys. 355(1-4), 99-126.

Samson, C., P. Barton, and J. Karwatowski: 1995, 'Imaging beneath an opaque basaltic layer using densely sampled wide-angle OBS data'. Geophys. Prospect. 43, 509-527.

voeringPapier_corr2_net.tex; 31/10/2005; $17: 25 ;$ p.28 
Schlindwein, V., C. Bnnemann, C. Reichert, I. Grevemeyer, and E. Flueh: 2003, 'Three-dimensional seismic refraction tomography of the crustal structure at the ION site on the Ninetyeast Ridge, Indian Ocean'. Geophys. J. Int. 152, 171-184.

Talwani, M., J. Worzel, and M. Landisman: 1959, 'Rapid gravity computations for two-dimensional bodies with application to the Mendocino submarine fracture zone'. J. Geophys. Res. 64, 49-59.

Torne, M., M. Fernandez, W. Wheeler, and R. Karpuz: 2003, 'Three-dimensional crustal structure of the Voring Margin (NE Atlantic): A combined seismic and gravity image'. J. Geophys. Res. 108(B2), 2115.

Verhoef, J., W. Roest, R. Macnab, J. Arkani-Hamed, and members of the Project Team: 1996, Magnetic anomalies of the Arctic and North Atlantic Oceans and adjacent areas. Geological Survey of Canada.

Wessel, P. and W. Smith: 1991, 'Free software helps map and display data'. Eos Trans. $A G U \mathbf{7 2 ( 4 4 1 ) , 4 4 5 - 4 4 6 .}$

Zelt, C. and P. Barton: 1998, 'Three-dimensional seismic refraction tomography: a comparison of two methods applied to datat frpm the Faeroe Basin'. J. Geophys. Res. 103, 7187-7210.

Zelt, C. and D. Forsyth: 1994, 'Modeling wide-angle seismic data for crustal structure: Southeastern Grenville Province'. J. Geophys. Res. 99(B6), 11,687-11,704.

Zelt, C. and R. Smith: 1992, 'Seismic traveltime inversion for 2-D crustal velocity structure'. Geophys. J. Int. 108, 16-34.

voeringPapier_corr2_net.tex; 31/10/2005; $17: 25 ;$ p.29 


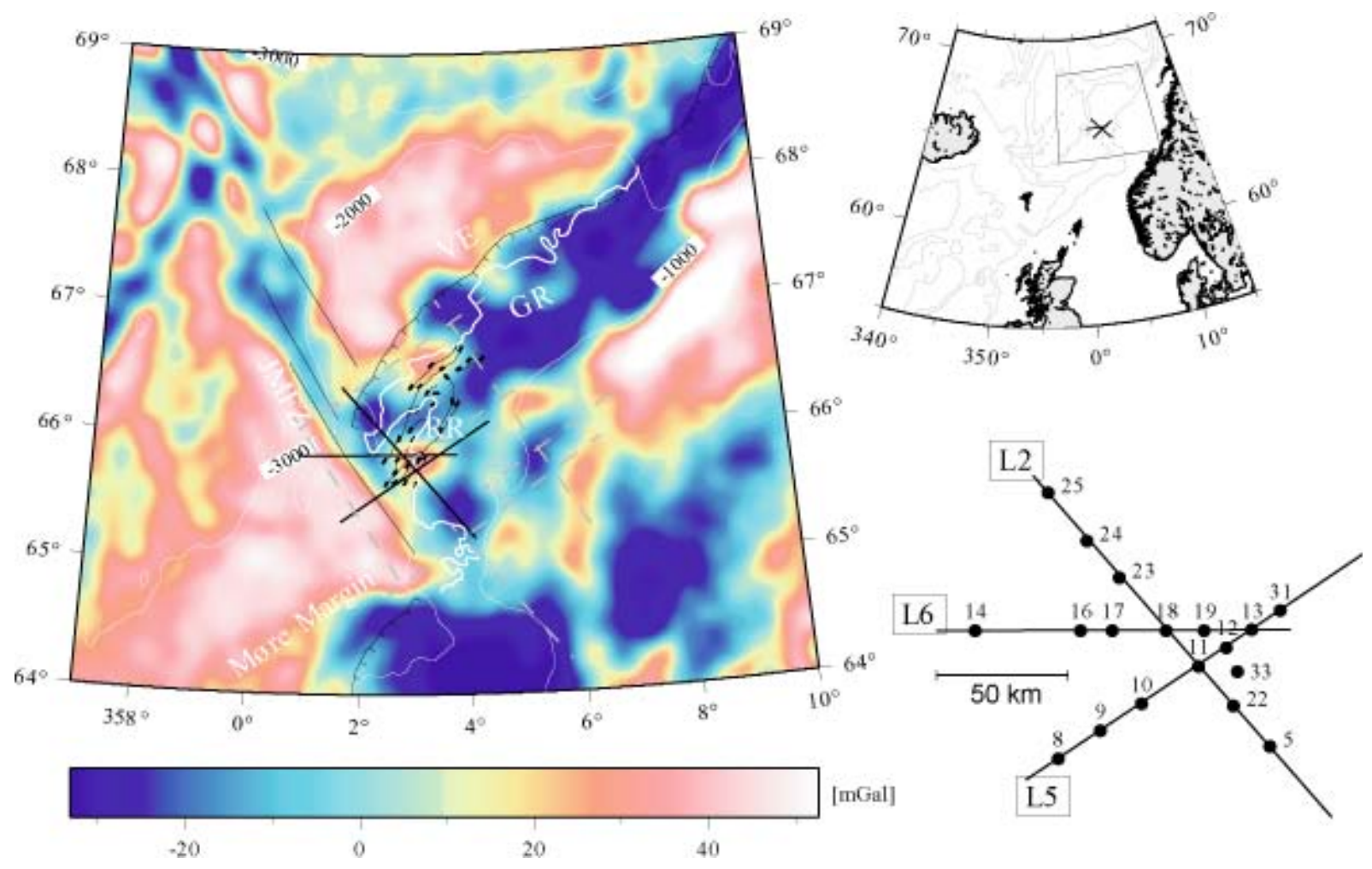

Fig. 1 Satellite-derived free air gravity map (Andersen and Knudsen 1998) of the Vøring Basin, centred on the Vøring 2000 experiment, and location of the OBS and seismic lines, crossing over the $\mathrm{Ra}^{\circ} \mathrm{n}$ Ridge gravity high. Thin white lines are bathymetric contours every $1,000 \mathrm{~m}$ and grey dashed lines are the 1996 WAS profiles. The thick white line is the landward extent of the inner flows (modified from Berndt et al. 2001a). The interpretation of the main early Cretaceous normal faults defining the $\mathrm{Ra}^{\circ} \mathrm{n}$ Ridge is shown as black lines (from Gernigon et al. 2003). VE, Vøring Escarpment; RR, Ra ${ }^{\circ}$ Ridge; GR, Gjallar Ridge 

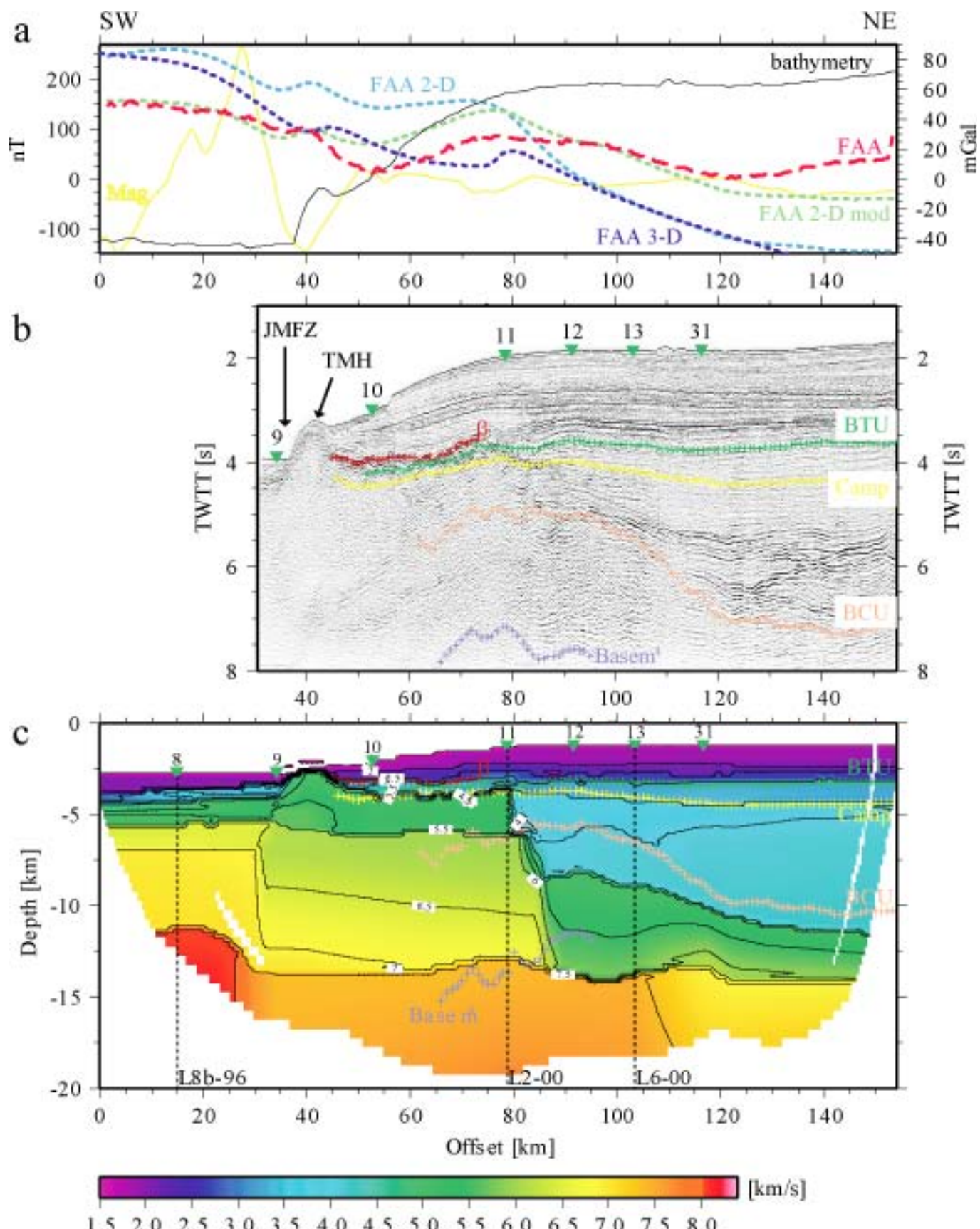

Fig. 2 (a) Plot of the bathymetry (thin black line), shipboard free air gravity anomaly (FAA, dashed red line) and magnetic anomalies (yellow line, Verhoef et al. 1996) along line L5. The light blue dotted line (FAA 2-D) is the predicted FAA corresponding to the 2-D velocity model presented in (c). The green dotted line (FAA 2-D mod) is the predicted anomaly when a Moho is introduced, warranting an isostatic equilibrium. The dark blue dotted line (FAA 3-D) is the FAA modelled from the 3-D velocity model, cf. Section 3-D modelling. (b) MCS profile coincident with L5. Inverted triangles at the seabottom are the OBS positions; the vertical dashed lines are the intersections with lines L2 and L6. Coloured horizons are part of the geological interpretation provided by TotalFinaElf Norge, based on a comprehensive set of close MCS profiles. TMH, Transform Margin High; BTU, Base of Tertiary Unconformity; Camp, Intra-Campanian horizon; BCU, Base of Cretaceous Unconformity. Notice the rough surface of the flood basalts top (b) and the attenuated reflectivity below. (c) Velocity structure inferred from the modelling of the WAS data. Coloured surface is actually crossed by seismic rays. The coloured lines are the same MCS horizons as in (b), after being converted to depth using the present velocity model. Notice the drastic change in the velocity below OBS 11 and the large misfit between the BCU and the $5-\mathrm{km} / \mathrm{s}$ interface 

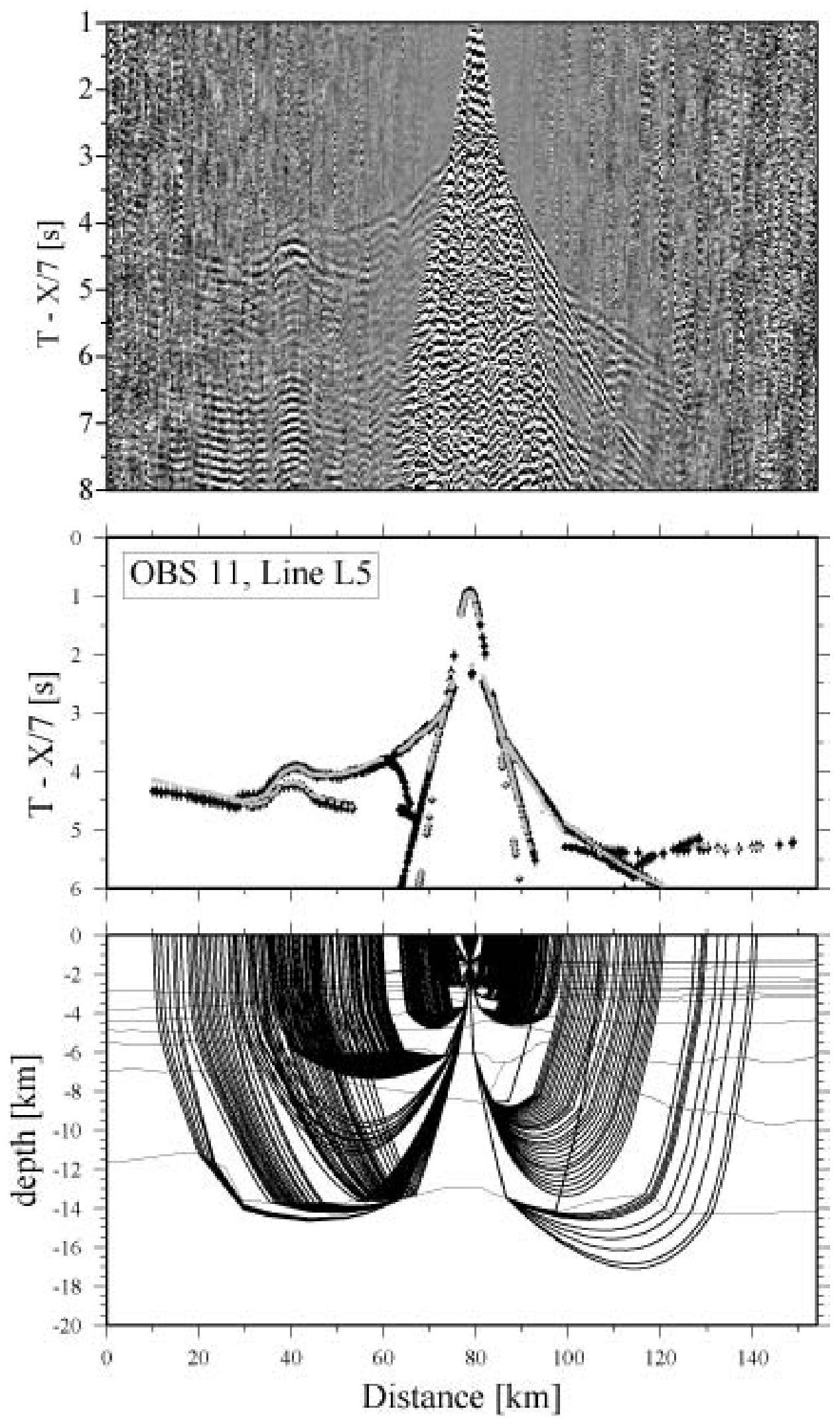

Fig. 3 (a) OBS 11 gather plotted with time and offsetdependent amplitude correction, for a reduction velocity of $7 \mathrm{~km} / \mathrm{s}$. The asymmetry in the travel times on either side of the OBS reflects much higher velocities on the left-hand side. Notice the topographic effect of the transform margin high at $x=40 \mathrm{~km}$. (b) Picks of the different phases (black crosses) and related synthetic travel times after modelling (gray crosses). (c) Velocity interfaces and ray paths associated to the synthetics travel times shown in (b) 

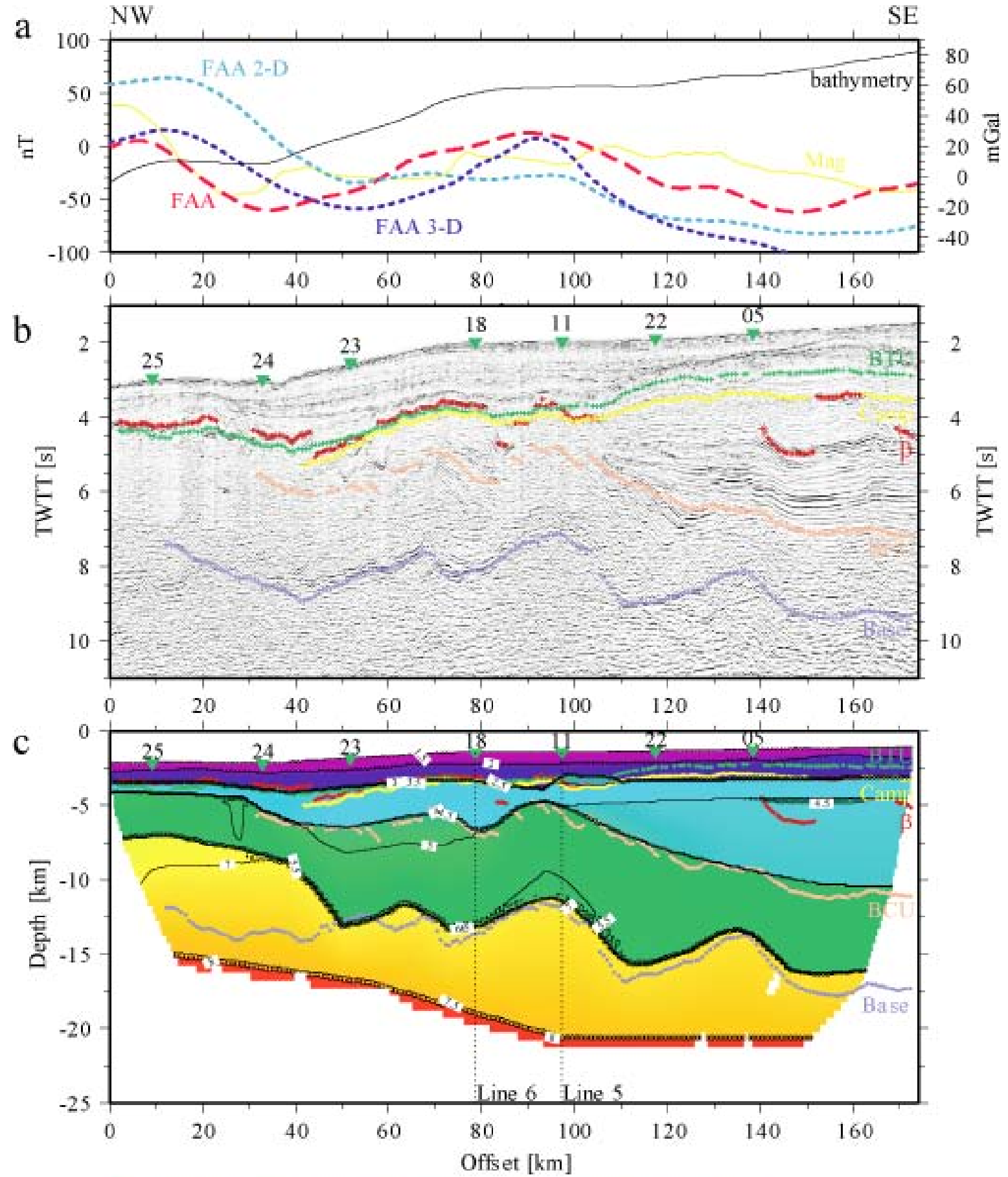

$[\mathrm{km} / \mathrm{s}]$

$\begin{array}{lllllllllllllll}1.5 & 2.0 & 2.5 & 3.0 & 3.5 & 4.0 & 4.5 & 5.0 & 5.5 & 6.0 & 6.5 & 7.0 & 7.5 & 8.0\end{array}$

Fig. 4 Same display as in Fig. 2, but for line L2. (a) Bathymetry (solid black line), satellite-derived FAA (red dashed line) and magnetic anomaly (solid yellow line), and predicted 2-D and 3-D derived FAA (respect. light blue and dark blue dotted lines). (b) MCS profile coincident with WASline L2. Same horizons as in Fig. 2b. $b$ (dark red dots) points indistinctly onto the flood basalts (above the BTU) and sills. A sill complex is reported right below OBS 11 at $4 \mathrm{~s}$ TWT. The depth of the BCU below the basalts and the basement is derived from surrounding profiles. (c) 2-D velocity model with MCS horizons restretched to depth. Note that the MCS-interpreted basement coincides with the $7-\mathrm{km} / \mathrm{s}$ interface. A v2 of 1.5 for a RMS error of $0.113 \mathrm{~s}$ is reached if the two deeper horizons are removed. If included, the v2 remains as high as 5.308 for a RMS of $0.227 \mathrm{~s}$ 

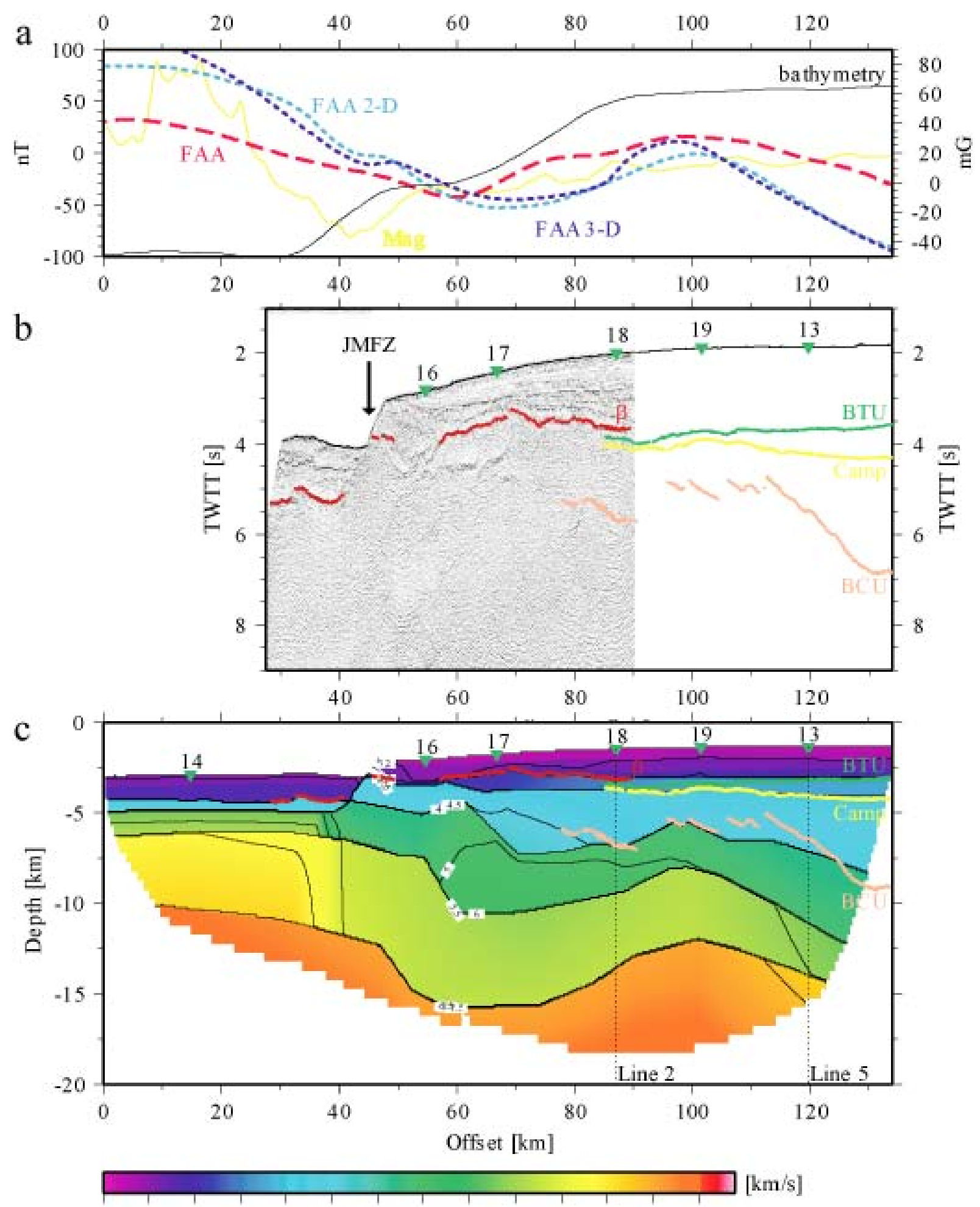

$\begin{array}{llllllllllllll}1.5 & 2.0 & 2.5 & 3,0 & 3.5 & 4.0 & 4.5 & 5,0 & 5,5 & 6,0 & 6.5 & 7.0 & 7,5 & 8.0\end{array}$

Fig. 5 Same display as in Fig. 2, but for line L6. (a) Bathymetry (solid black line), observed FAA (red dashed line) and magnetic anomaly (solid yellow line), and predicted 2-D and 3-D derived FAA (respect. light blue and dark blue dotted lines). (b) MCS profile coincident with WAS-line L6. (c) 2-D velocity model with MCS horizons restretched to depth 

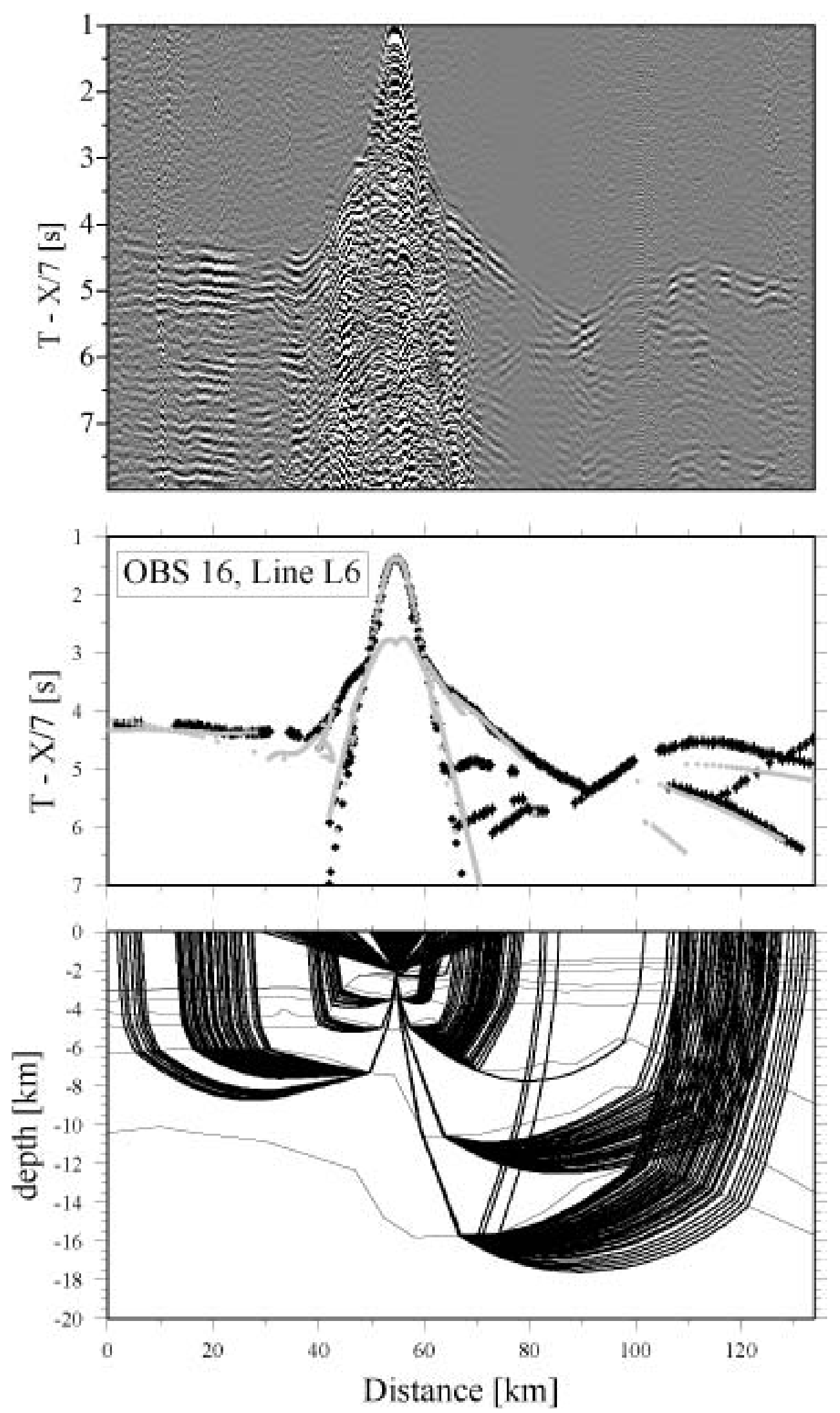

Fig. 6 OBS gather 16, along line L6. The interpretation/ synthetics and ray paths are shown similar to Fig. 3. The large bump in the first arrivals on the right-hand side constrains the large uplift of the 7$\mathrm{km} / \mathrm{s}$ interface below OBS 19 (cf. Fig. 5c); the best fit is obtained using a head wave travelling along the $7-\mathrm{km} / \mathrm{s}$ interface 

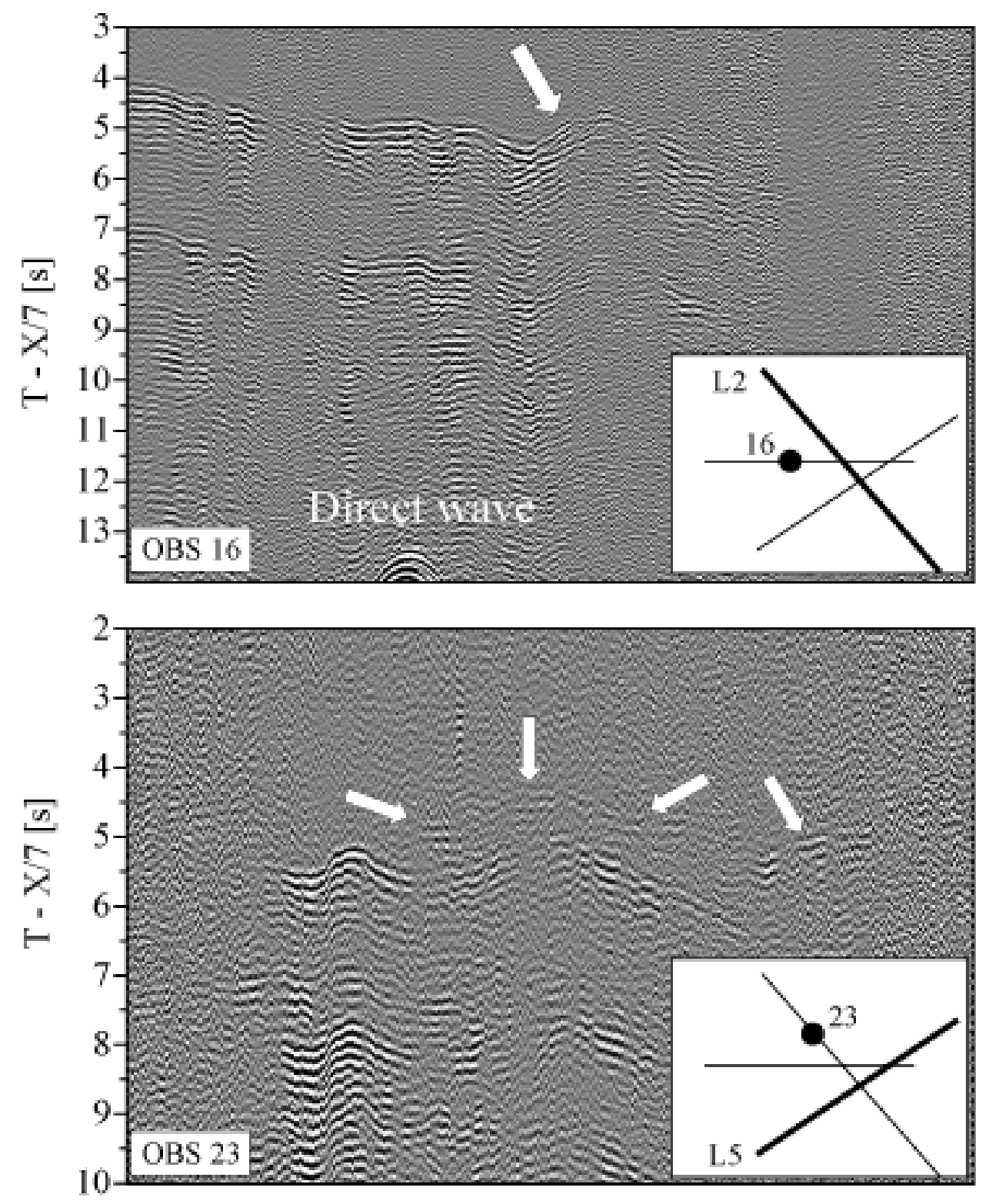

Fig. 7 Examples of 3-D WAS data: (a) OBS 16 recording shots along L2 (see Fig. 1 for location). The direct wave (water wave) at the bottom of the seismogram gives the location of the OBS projected on the seismic line (shortest offset). A reduction velocity of $7 \mathrm{~km} / \mathrm{s}$ is applied. The white arrow points toward a bump of the first arrivals denoting a local, but strong increase in the velocity somewhere between the OBS and the shots. (b) OBS 23 recording shots along L5. The shortest offset is around trace \# 550. This seismogram illustrates the difficulty of picking first arrivals; in this case, and after a trial-anderror approach, the first arrivals coherent with the other OBS appears to be the low amplitude signal highlighted by the white arrows. Notice the bright, characteristic signature of the transform margin high around shot \# 300 

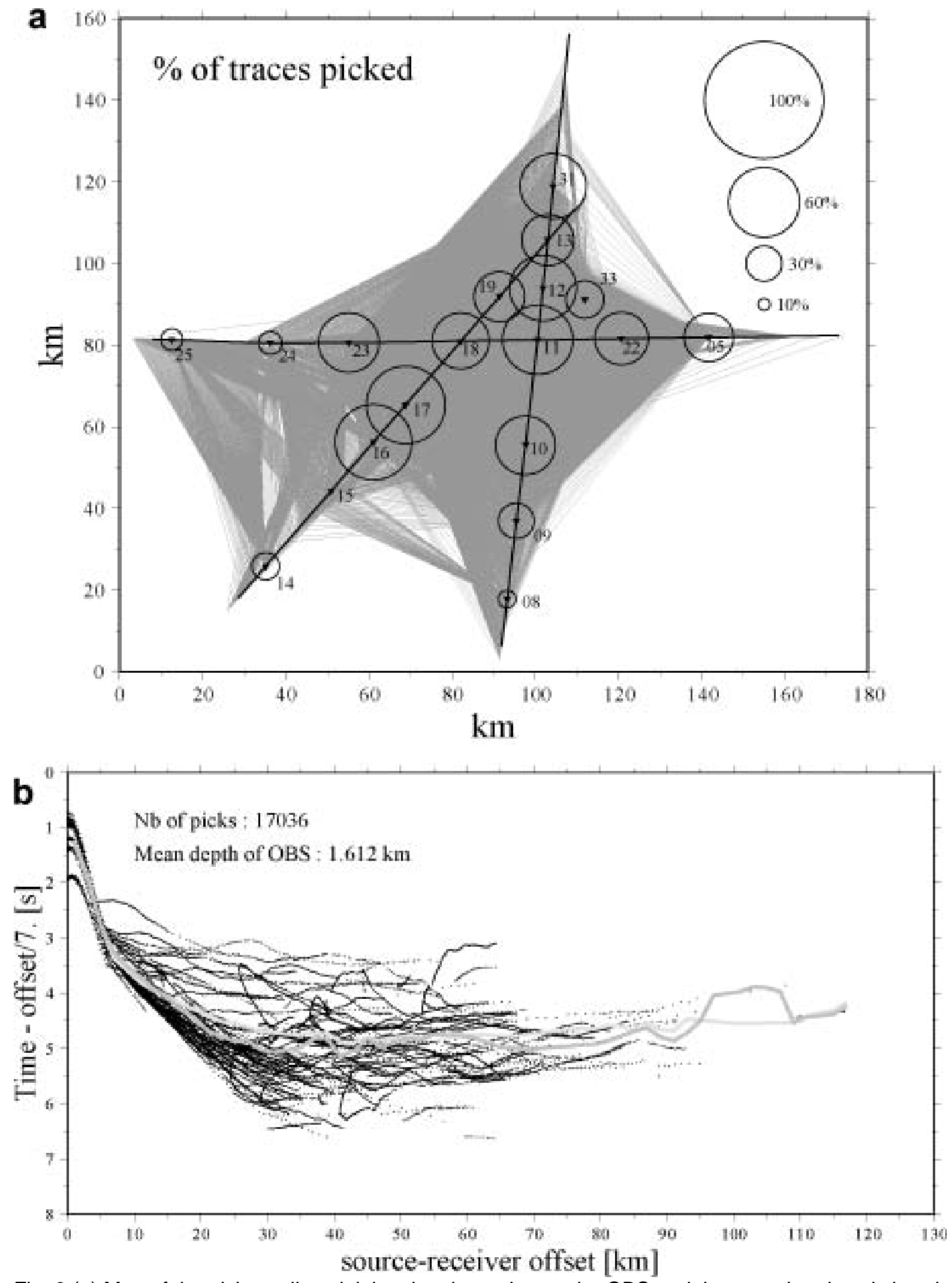

Fig. 8 (a) Map of the picks as lines joining the shot points to the OBS and the associated statistics: the circles show the percentage of traces picked for each OBS. Remote OBS in the oceanic domain show a poorer quality. (b) First arrival travel times picked versus offset (black dots). The dark gray line is the travel time averaged on $2 \mathrm{~km}$ wide bins. The light gray line is the travel time for rays travelling through the 1-D starting model 


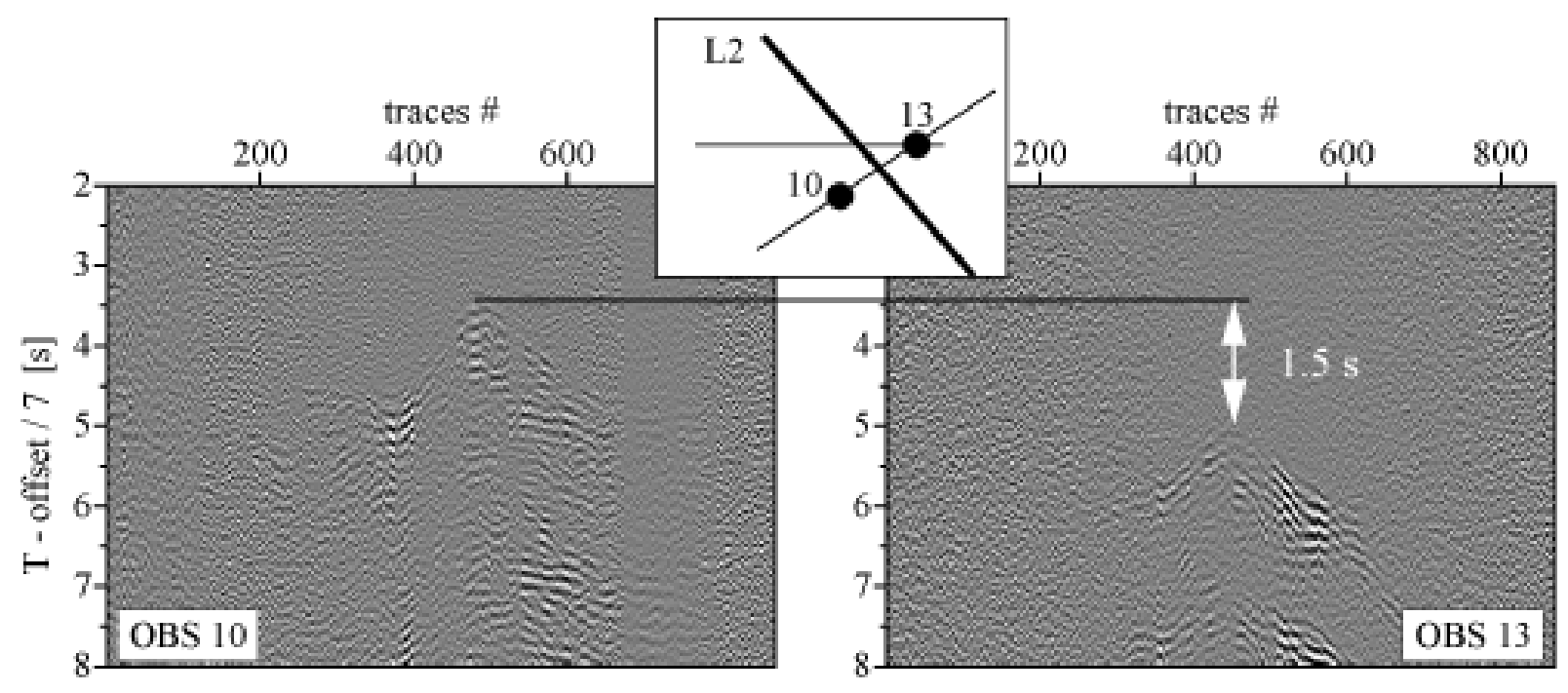

Fig. 9 Shots along L2 recorded by OBS 10 and 13. Both OBS are equally distant from the seismic line, but the first arrival on OBS 13 is delayed by at least $1.5 \mathrm{~s}$
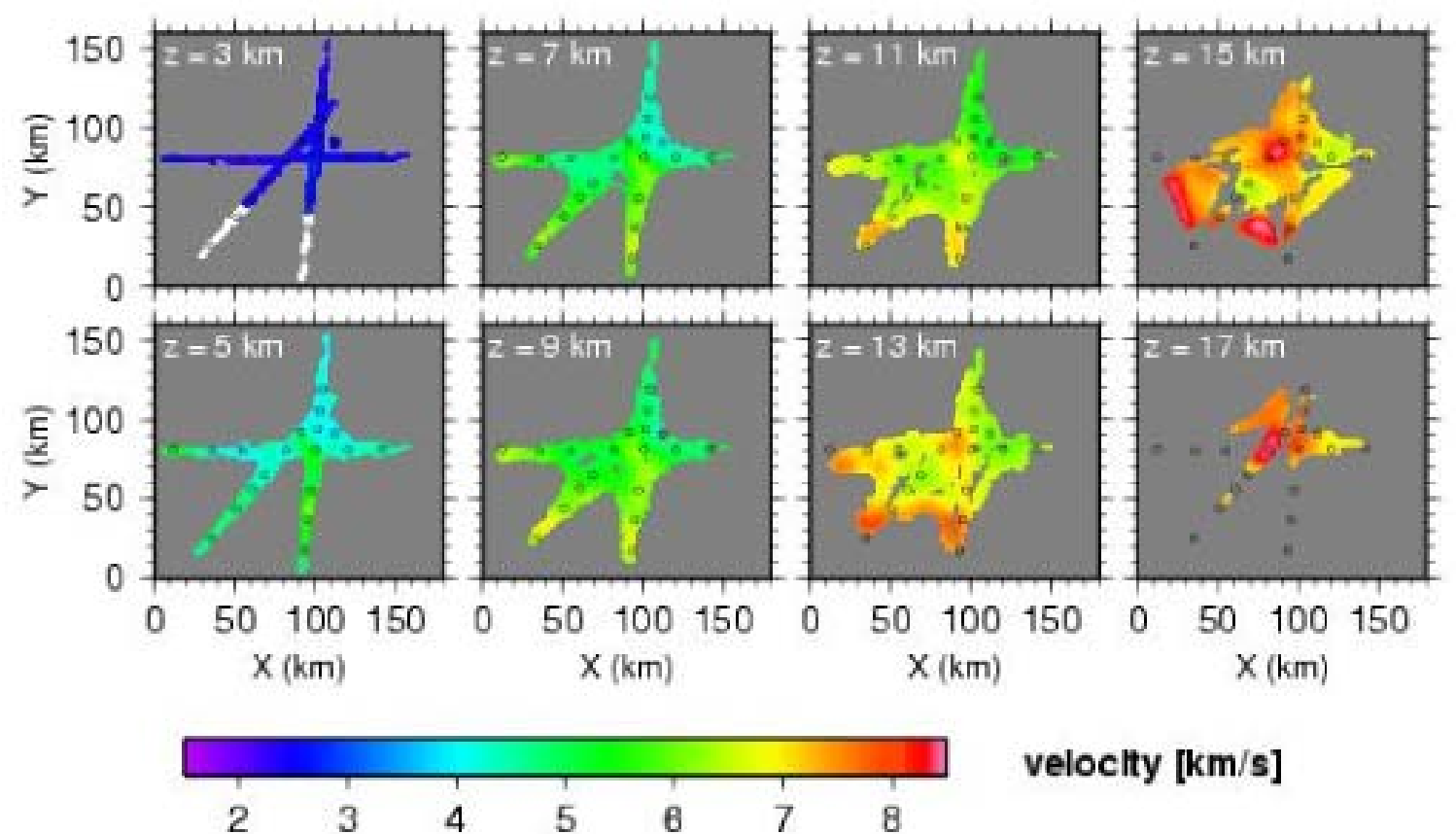

veloclty $[\mathrm{km} / \mathrm{s}]$

$10-\mathrm{a}$ 

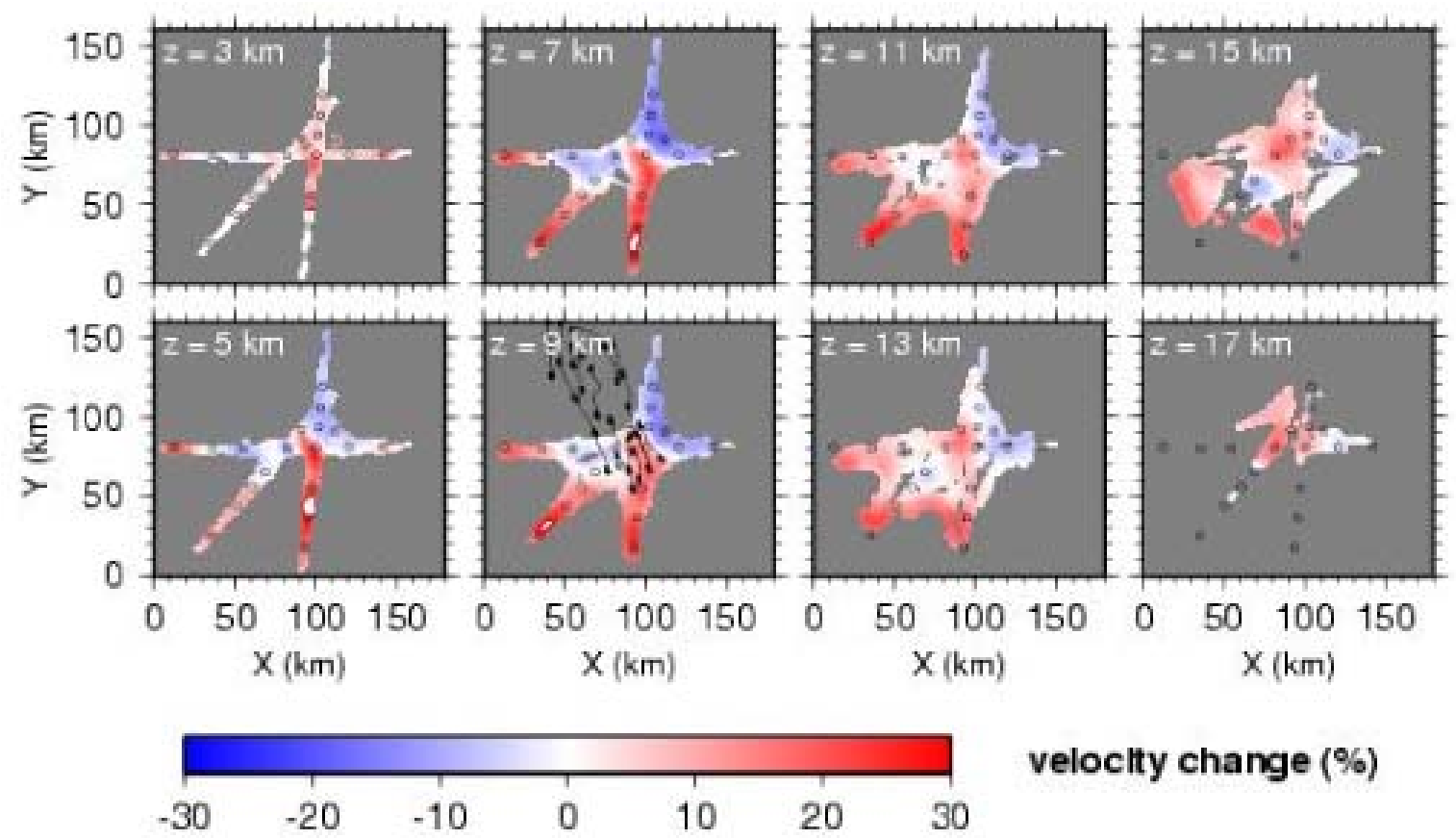

10-b
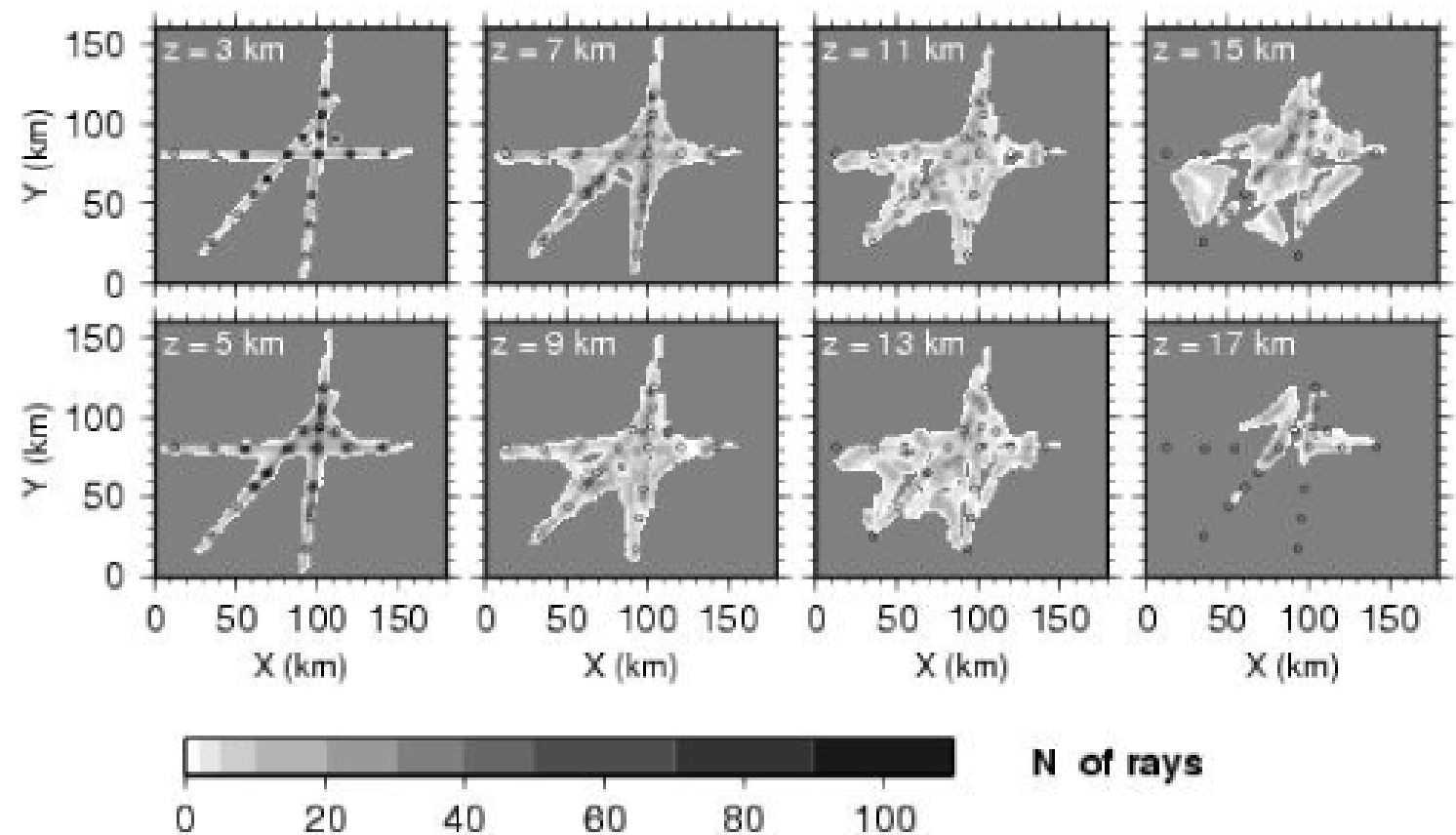

$\mathrm{N}$ of rays

10-c 


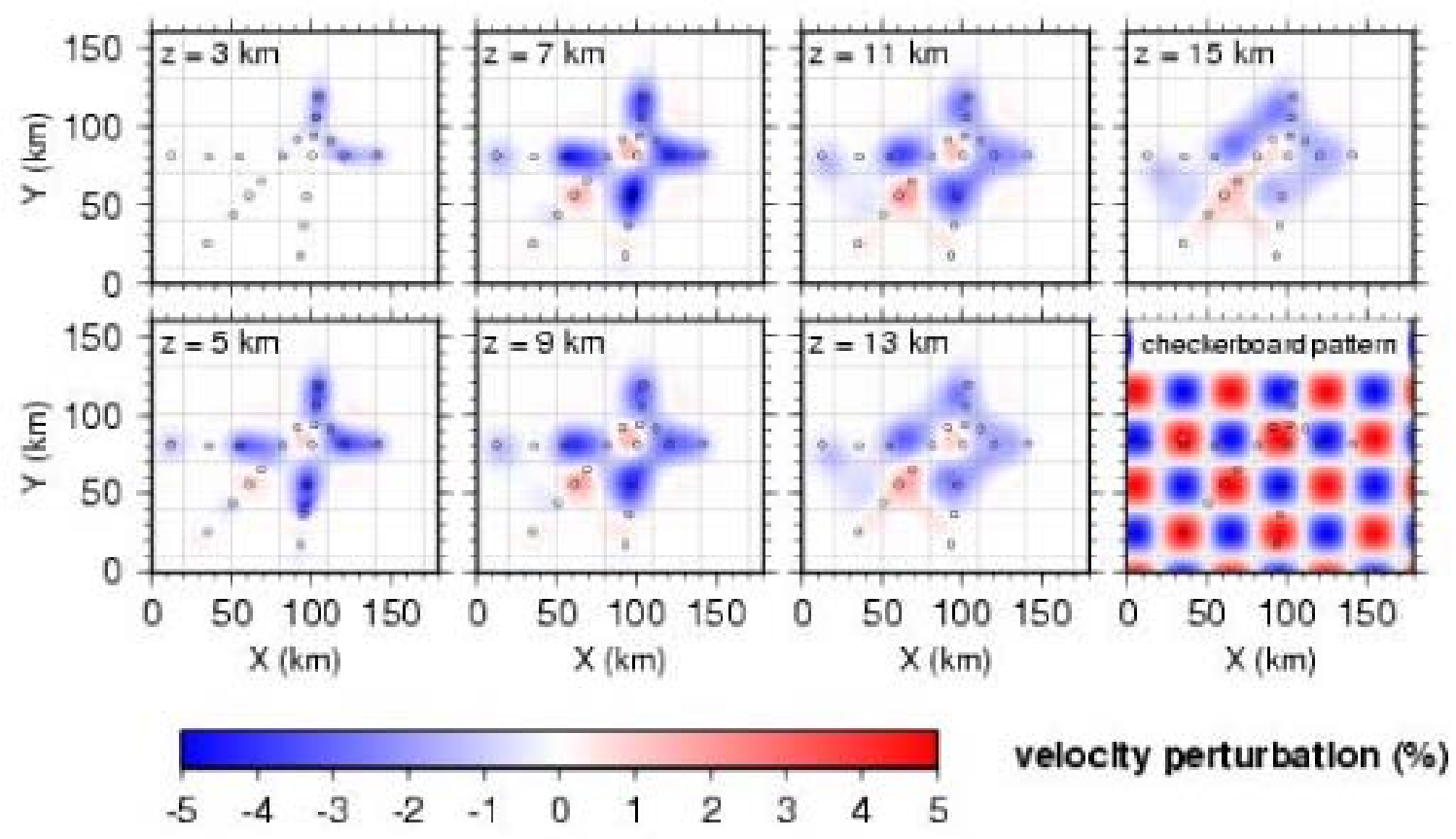

$10-d$

Fig. 10 Horizontal slices across the final velocity model after five iterations. Panel (a) is the velocity $(\mathrm{km} / \mathrm{s})$, panel (b) is the relative change between the starting model and the final model (\%), panel (c) is the related ray coverage (number of rays) and panel (d) is the checkerboard test for a $60 \mathrm{~km}$ wavelength (the lower right slice is the checkerboard pattern). Open circles are OBS positions. Faults interpreted by Gernigon et al. (2003, cf. Fig. 1) are plotted in panel (b) on the $9 \mathrm{~km}$ depth slice; the position and orientation of the velocity change below OBS 11 is in good agreement with the faults forming the $\mathrm{Ra}^{\circ} \mathrm{n}$ Ridge 


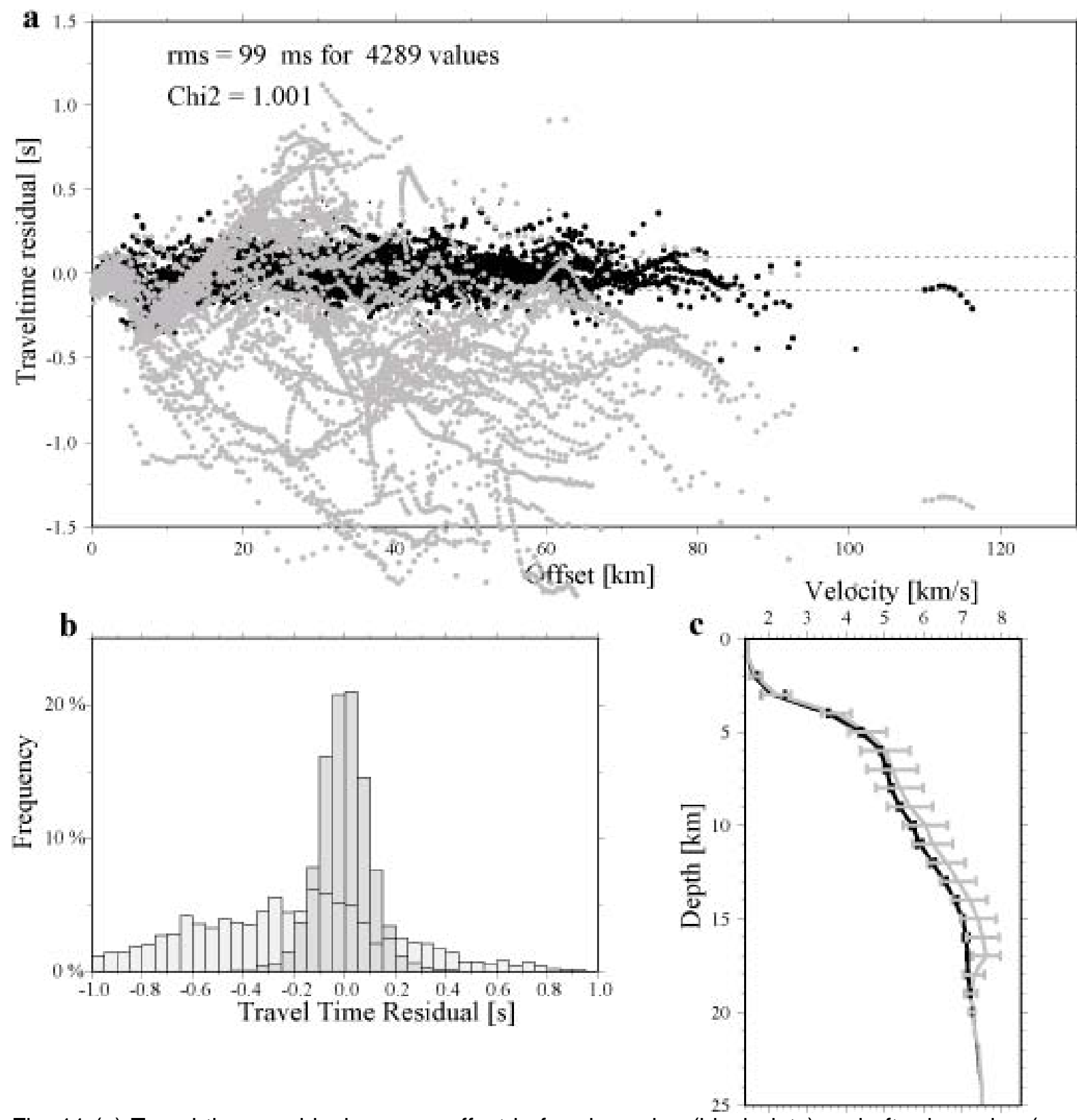

Fig. 11 (a) Travel time residuals versus offset before inversion (black dots) and after inversion (gray dots). The two thin lines show the -100 ms interval of the uncertainty. (b) Statistical distribution of the residuals before inversion (light grey) and after inversion (dark grey). (c) Vertical profile of the horizontally averaged velocity before inversion (black) and after inversion (gray). Horizontal segments indicate the standard deviation 


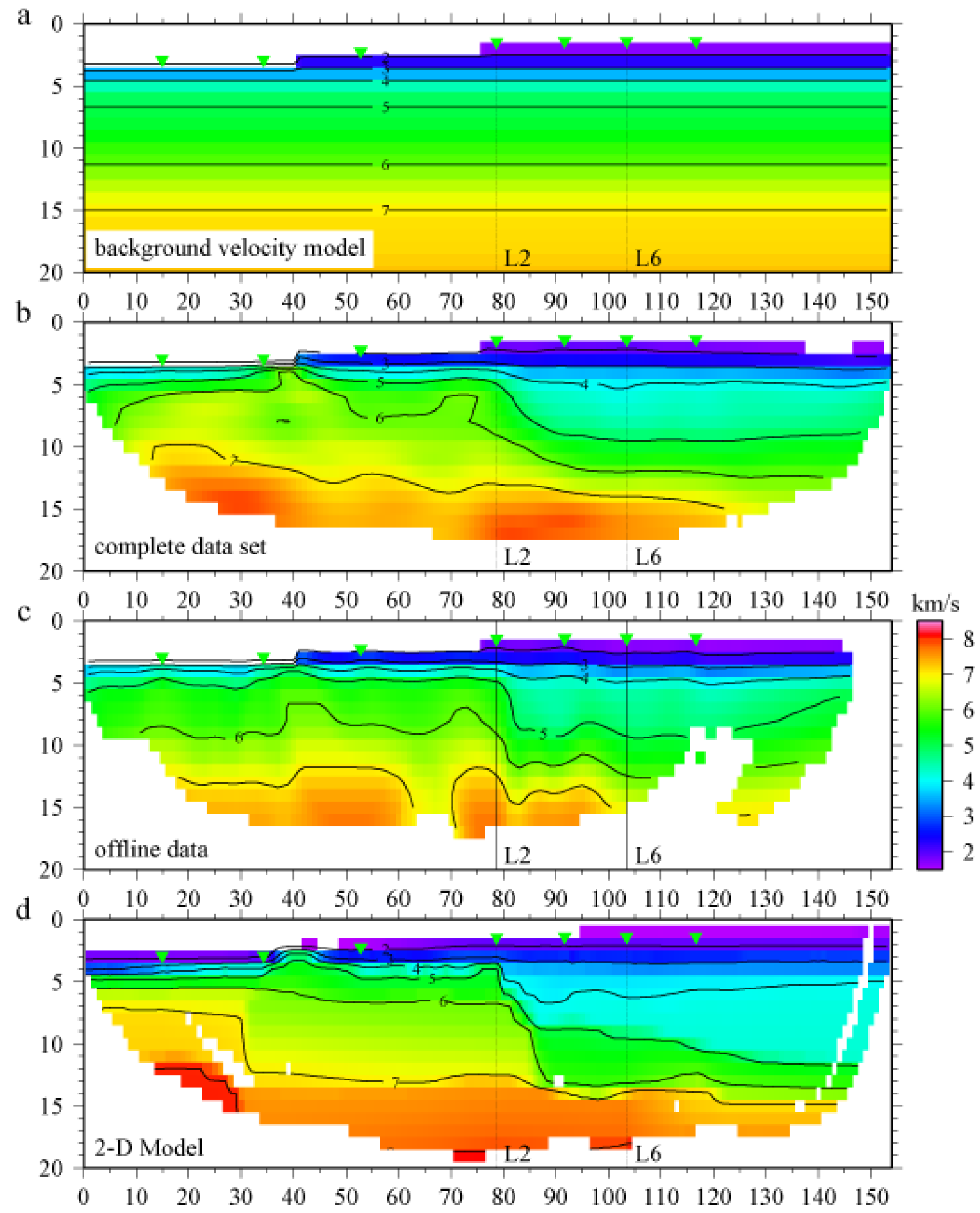

Fig. 12 Vertical slice across final models coincident with 2-D line L5. (a) Starting model; (b) final model using the complete data set; (c) final model using only the off-line data; and (d) velocity model inferred from the 2-D modelling (same as Fig. 2c) 

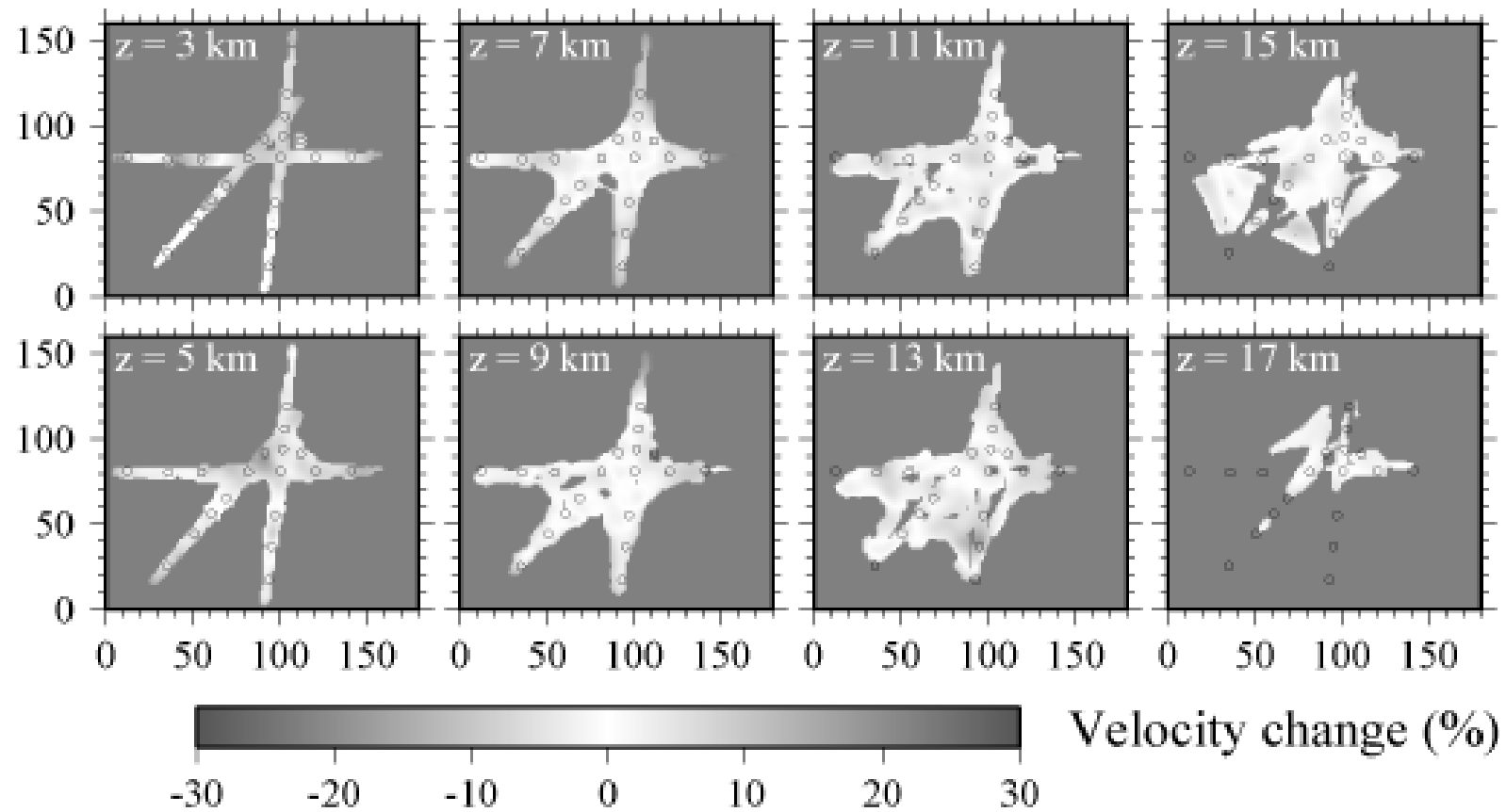

Velocity change (\%)

Fig. 13 Difference between the solution obtained using the 3-D starting model and the solution obtained using the 1-D starting model (same display as in Fig. 10)

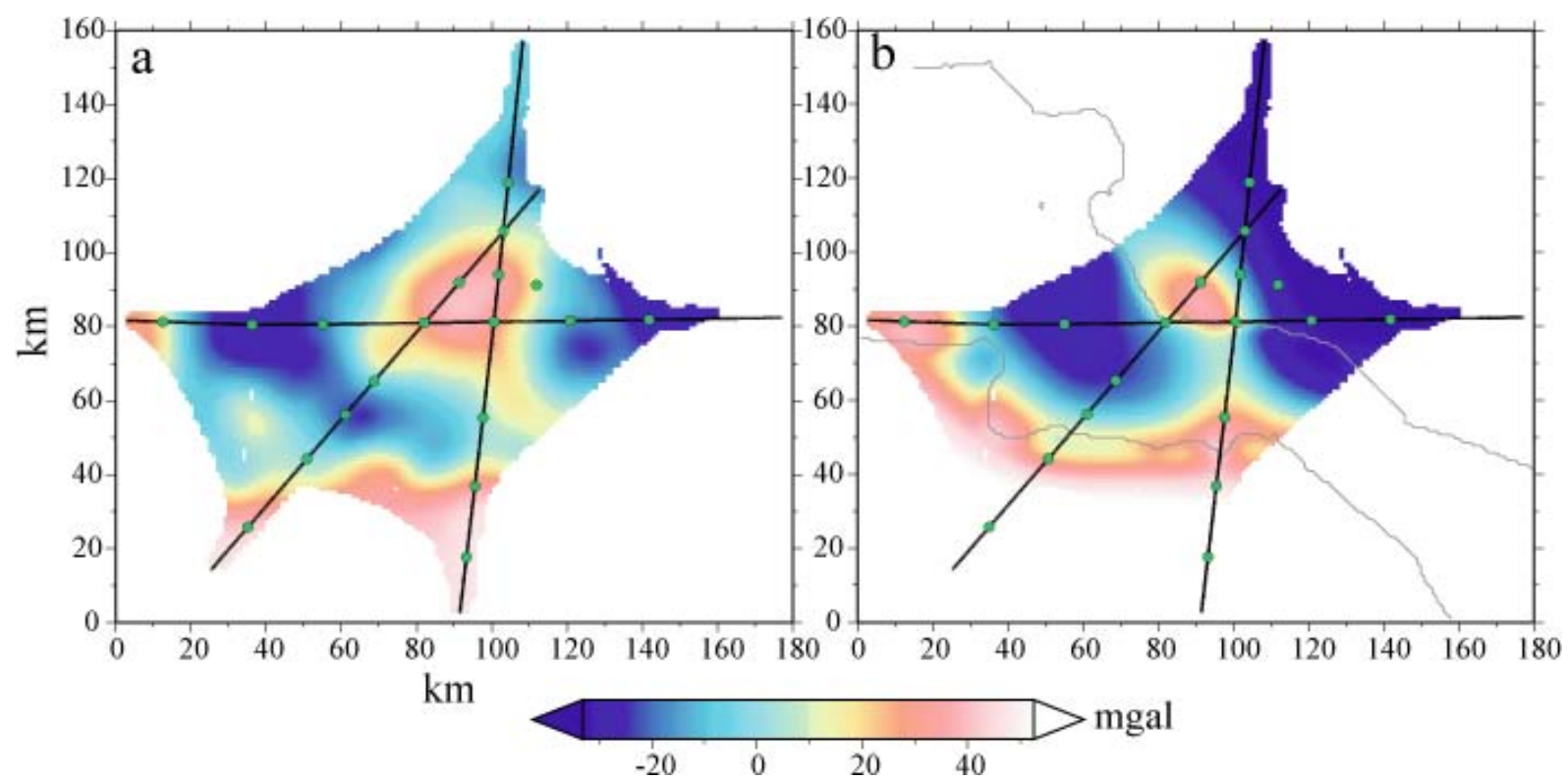

Fig. 14 Map of the observed (a) and predicted (b) free-air gravity anomaly. The predicted anomaly is estimated from the 3-D velocity model. A mask shows only areas where velocities are constrained. The grey curly lines show the $1 \mathrm{~km}$ high steps of the discretised bathymetry. Anomalies along the seismic lines have been extracted and are shown in Figs. 2a, 4a and 5a. A long wavelength is present in the predicted anomaly, mainly in the direction perpendicular to the fracture zone; the 2-D modelling showed that an isostatic Moho would strongly attenuate this trend (cf. Fig. 2a) 